\title{
Physical characteristics of very small meteoroids
}

\author{
J.-B. Kikwaya ${ }^{1,2}$, M. Campbell-Brown ${ }^{2}$, P. G. Brown ${ }^{2}$, R. L. Hawkes ${ }^{3}$, and R. J. Weryk ${ }^{2}$ \\ 1 Vatican Observatory, 00120, Vatican City State, Italy \\ e-mail: jbkikwaya@free.fr \\ 2 Department of Physics and Astronomy, University of Western Ontario, 1151 Richmond St., London, ON N6A 3K7, Canada \\ 3 Physics Department, Mount Allison University, 67 York St., Sackville, NB E4L 1E6, Canada
}

Received 21 August 2008 / Accepted 3 February 2009

\begin{abstract}
We have optically recorded faint meteors using a large aperture LLLTV (low light level television) system based on second generation image intensifiers. These data consist of 42 two-station meteors of which 13 were captured during an observing campaign near London, Ontario (Canada) in May 2004, and 29 during a campaign near Kiruna (Sweden) in October 2007. Among 13 meteors recorded in the London campaign, where the baseline between the two sites was $5 \mathrm{~km}$, only four meteors satisfied our requirement for complete lightcurves and deceleration profiles by starting in the field of view, of at least one station and also ending in the field of view of at least one station. From the second set of 29 meteors captured in Sweden, with a baseline of $117.7 \mathrm{~km}$, only two satisfied these criteria. The cameras used in both campaigns had fields of view of 6 degrees, which with an assumed range of $100 \mathrm{~km}$, gives a scale of $13 \mathrm{~m} / \mathrm{pixel}$ at $\sim 60$ interlaced fields per second. This resolution allows precise measurement of the deceleration of very faint meteors. The limiting magnitude for meteors on these systems is near $V=+8$, while +11 th magnitude stars are visible in the individual fields. The meteors detected in these two campaigns have peak brightnesses between absolute magnitude +6.2 and +7.4 . Their photometric masses range from $4.2 \mathrm{mg}$ to $0.35 \mathrm{mg}$. An ablation model was applied to fit each complete two-station event using the high-precision metric and photometric data as a constraint, in an attempt to compute bulk meteoroid densities. Interestingly, a large proportion of our faint meteor events were found to ablate at low altitudes, a result partly of our observing biases. The orbits of these events are consistent with either asteroidal or a Jupiter-family comet origin. The meteoroids' physical properties, as determined through model fits, suggest high densities, which favors an asteroidal interpretation. The high percentage of apparently dense asteroidal meteoroids at these small sizes may call into question earlier findings that only $\sim 1 \%$ of meteoroids at these masses are asteroidal in origin. Our results are similar to others that find $\sim 15 \%$ of faint TV meteors had spectra consistent with pure iron meteoroids. We find that many of these apparently asteroidal objects also undergo extensive fragmentation, which may reflect melting and spraying of droplets rather than mechanical fragmentation. Some individual cases in our small dataset will be highlighted where high bulk densities (approaching that of iron) are required to adequately match the end height, peak brightness, and observed deceleration. We speculate that these meteoroids may represent metallic condensates from impact-processed asteroid regolith.
\end{abstract}

Key words. meteors, meteoroids

\section{Introduction}

An important physical property of meteoroids is their density. Knowing it can help determine the physical structure and potentially the chemical composition of their parent bodies. However, determining meteoroid density is not an easy task. It might be easy to find the density of a solid, uniform sphere ablating in the atmosphere (assuming the body enters the atmosphere as a solid with a spherical shape, ablates uniformly, and remains a single solid body during the whole of its flight), but ablation modeling is complicated by the fact that meteoroids fragment and have unknown shapes, structures, and chemical compositions.

When a meteoroid comes into contact with the earth's atmosphere, it ablates and generates electromagnetic radiation, including visible light. The height of ablation is influenced by many factors, including the entry angle, the speed of the meteoroid, its mass, the energy required to ablate the material of which it is composed, its boiling point, its structure, and its bulk density (Campbell-Brown \& Koschny 2004).

It has long been known that the ablation behaviour among meteoroids differs considerably. These differences are reflected in different beginning heights, lightcurve shapes and, for larger meteoroids, in end height differences for meteoroids of similar speed and mass (cf. Ceplecha et al. 1998, for a complete discussion). It has long been assumed that these differences have to do with the physical characteristics of each meteoroid, including its composition, structure, bulk density and size: for example Koten et al. (2004) used the lightcurves and heights of video meteors to find significant differences among meteors from major showers. They argue that this suggests the parent bodies have different chemical compositions or physical structure.

The interpretation of all of these data is substantially complicated by the process of fragmentation. Besides the question of whether or not small meteoroids undergo fragmentation, the process of fragmentation itself remains an open question. Does fragmentation occur before the onset of, or during rapid vaporization? Does it happen at a critical temperature or a critical pressure?

Campbell et al. (2000) argued that fragmentation occurs before the process of ablation starts. Only after grains have been released from the main mass do they undergo intensive ablation. This is consistent with the dustball meteoroid model (Hawkes \& Jones 1975), in which meteoric bodies are assumed to be composed of grains held together by a lower boiling point "glue": when the binding melts, the grains are released. Further support for the dustball model comes from the weak dependence of the 
beginning height, maximum height and trail length of the visible meteor on the mass of the meteoroid, as found in studies by Campbell et al. (2000), Koten et al. (2004), Hapgood et al. (1982) (for Perseids fainter than $M v=0$ ) and Beech (1986) (for Draconid meteors). The dustball model predicts that grains of different masses which are ejected from the meteoroid will decelerate at different rates, producing physical wake from the spread in the grains. Fisher et al. (2000) confirmed that half of the video meteors they investigated showed this wake when observed with short effective exposures.

Clearly, the mechanism of fragmentation for meteoroids is complex and much of contemporary meteoroid ablation modelling concentrates on attempting to formalize the process. Campbell-Brown \& Koschny (2004) suggested that fragmentation occurs when the temperature of the surface is high enough to disrupt the binding matrix of the meteoroid; the top layer of the meteoroid (to a depth determined by the assumed thermal conductivity) is released all at once.

In a study of six Draconid meteors for which deceleration and photometric measurements were available for the first time, Borovička et al. (2007) suggested that grain separation started after the surface of the meteoroid received a certain energy flux, calculated to be $10^{6} \mathrm{~J} \mathrm{~m}^{-2}$; this is physically equivalent to requiring the surface to reach a particular temperature. The meteoroid then gradually fragments into grains over the first half of its trajectory, a process Borovička et al. (2007) call thermal erosion. Meteoroids resistant to this process may disrupt at low dynamic pressures.

Beech \& Murray (2003) used the dustball model to generate synthetic Leonid lightcurves. They matched different shapes of lightcurves to synthetic lightcurves generated by a power law distribution of grains, from $10^{-10} \mathrm{~kg}$ up to $10 \%$ of the total mass (which was taken to be $10^{-6} \mathrm{~kg}$ ), varying the mass distribution index between 1.0 to 2.0. They suggested that the 1999 Leonid meteoroids were relatively rich in larger-mass fundamental grains.

While several studies of the overall physical structure of meteoroids have produced qualitative support for the dustball model, quantitative measurements of the bulk density of meteoroids are more difficult to make, again due to the variety of ways fragmentation may be handled in modelling. Ceplecha (1968) calculated the density of small meteoroids and classified them into four categories (A, B, C, D) based on a parameter, $K_{\mathrm{B}}$, which depends on the atmospheric density at the beginning of the luminous trajectory, the initial velocity and the elevation of the radiant. Categories A through D were attributed to meteoroids having densities from 2700 to $180 \mathrm{~kg} \mathrm{~m}^{-3}$.

Babadzhanov (2002) examined 413 photographic super-schmidt meteors and applied a model which assumed quasi-continuous fragmentation (QCF). They found meteoroid densities between $400 \mathrm{~kg} \mathrm{~m}^{-3}$ and $7800 \mathrm{~kg} \mathrm{~m}^{-3}$. Bellot Rubio et al. (2002) questioned the validity of these high densities for small meteoroids. He singled out two questionable assumptions which led Babadzhanov (2002) to these results. The first is the fact that QCF is based essentially on fitting a model to the lightcurve, without taking into consideration the dynamical properties of the meteoroids, particularly the deceleration. The second was that the specific energy of fragmentation used by Babazhanov (2002) was underestimated by at least a factor of 10. Bellot Rubio points out that, with such a small heat of fragmentation, the meteoroid will always fragment before reaching the "real" heat of ablation. Analyzing the same meteors using the single body theory (assuming none of the meteoroids fragment), Bellot Rubio et al. (2002) found densities ranging from $400 \mathrm{~kg} \mathrm{~m}^{-3}$ to $4800 \mathrm{~kg} \mathrm{~m}^{-3}$. Since the characteristics of fragmentation are often observed in the lightcurves of small meteoroids as transient increases in brightness (including in the sample analysed by Bellot-Rubio et al. 2002), Borovička (2005) pointed out that this is a shortcoming of Bellot Rubio's work. Clearly, the lightcurves of meteoroids should be fit with a model that takes into account the dynamical properties of the meteoroids.

In this work, we adopt the dustball model as a first approximation to the physical structure of a meteoroid. We use the numerical model of ablation developed by Campbell-Brown \& Koschny (2004). This model is applied to high resolution measurements of lightcurves and astrometry for a suite of faint meteors observed from two stations. In particular, our measurement precision is high enough to allow routine observation of deceleration for faint (magnitude +7 ) meteors. This particular model uses eight free parameters to produce a theoretical lightcurve, and allows the velocity to vary with height along the meteoroid trajectory. We explore the solution space of all possible parameters and compute for each meteor hundreds of thousands of solutions whose lightcurves and decelerations are then compared to those observed. We find density limits for each meteor within which a solution can be found; from the number of solutions at each modeled density, we get a statistical measure of the density for each meteoroid and a measure of its error.

\section{Observations and equipment}

Data were collected during two different observing runs; one over three nights in Canada in May 2004, and one over seven nights in Sweden in October 2007. Second generation (Gen II) Litton microchannel plate image intensifiers with S-20 spectral response were used. Gen II intensifiers have a spectral response from $340-870 \mathrm{~nm}$ and have less sensitivity in the red, and shorter tube lifetimes, than Gen III intensifiers but are otherwise comparable. They are significantly more sensitive than Gen I intensifiers, and less susceptible to blooming when imaging bright point objects. Gen II intensifiers were used simply because they were simpler to integrate with the large lenses used in these campaigns. We used catadioptric lenses with $155 \mathrm{~mm}$ focal length and $\mathrm{f} / 0.75$ for both stations.

In the first campaign, two Deep Gen II cameras were installed at two different sites, which we call Elginfield Observatory $\left(43^{\circ} 11^{\prime} 58 \mathrm{~N}, 81^{\circ} 18^{\prime} 90 \mathrm{~W}\right)$ and the Silo site $\left(43^{\circ} 12^{\prime} 23 \mathrm{~N}, 81^{\circ} 22^{\prime} 62 \mathrm{~W}\right)$. The baseline between the two stations is $5.5 \mathrm{~km}$ and the cameras were pointed at the zenith, in order to cover a very large common volume of the sky. The baseline is much shorter than that typically used in video meteor observations, where cameras with fields of view (FOV) of 25 to 40 degrees are separated by 30 to $60 \mathrm{~km}$. This short baseline for our cameras, with their fields of view of 6 degrees, was motivated by the desire to maximize the number of two-station meteors completely observed by maximizing the common volume observed by the cameras: this also minimizes the height bias of the system. A longer baseline improves the precision, but produces almost no useful two station meteors, as seen by the results in the second campaign. The computation of different height precisions from different baseline values for two different camera FOVs shows that the deep genII with a FOV of 6 degrees, a baseline of $5.5 \mathrm{~km}$ and resolution of 0.008 degrees per pixel produces a height precision within $10 \%$ of that obtained with a baseline of $45.5 \mathrm{~km}$ and a typical LLLTV resolution of 0.054 degrees per pixel corresponding to a FOV of 35 degrees. Recognizing that the height errors alone are not the only uncertainty and that 


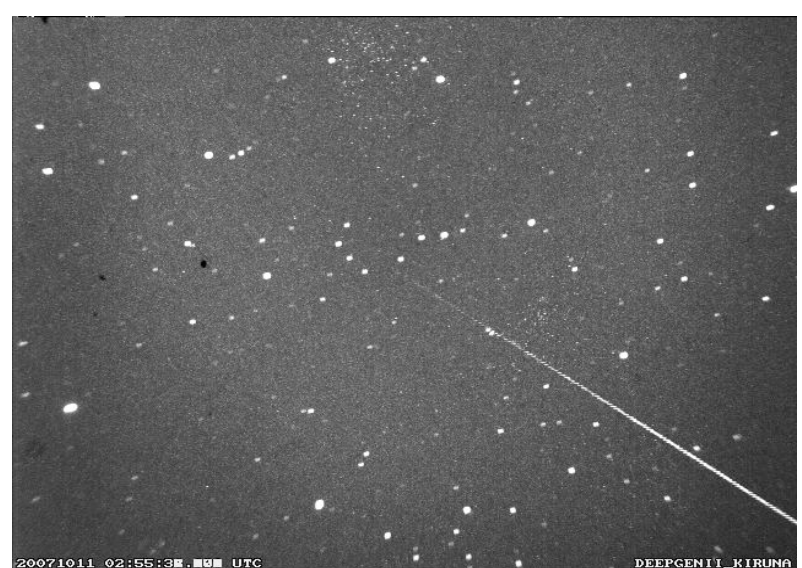

Fig. 1. Meteor captured in Kiruna (Sweden) on October 112007 at 02:55:32 UTC.

geometry comes into play in the trajectory solution, we examined all four events in detail from the short baseline campaign and introduced typical meteor measurement errors (of order 1 pixel) to all measured points in a monte carlo simulation run 10000 times. We find that in average the radiant error is $1.6 \mathrm{de}-$ grees; the height error $0.6 \mathrm{~km}$ and the velocity error $0.8 \mathrm{~km} \mathrm{~s}^{-1}$. This demonstrates that the shorter baseline is compensated by the higher resolution in terms of overall trajectory precision relative to typical LLLTV baselines.

In the second campaign, cameras were placed at Peera in Finland $\left(68^{\circ} 53^{\prime} 39 \mathrm{~N}, 21^{\circ} 3^{\prime} 34 \mathrm{E}\right)$ and at Kiruna in Sweden $\left(67^{\circ} 51^{\prime} 60 \mathrm{~N}, 20^{\circ} 25^{\prime} 98 \mathrm{E}\right)$. The baseline between the two stations is $117 \mathrm{~km}$. The main purpose of the second campaign was to look for simultaneous events with the EISCAT tristatic radar, so the geometry was not optimal for our purposes, but some of the data are still useful for this study.

The field of view of the images was $5.4^{\circ} \times 4.1^{\circ}$. The pixel dimensions of the video system are $720 \times 480$ pixels, producing a resolution of $\sim 30 "$ /pixel.

For a meteor $100 \mathrm{~km}$ from the camera, the systems had a resolution of $\sim 13 \mathrm{~m}$ per pixel with the full field of view being equivalent to linear dimensions of $9.5 \times 7.1 \mathrm{~km}$. We find that this is sufficient resolution at our small meteoroid sizes to show even very small decelerations. We used the CCD in an interlaced mode with 60 video fields (or 30 video frames) per second. The limiting stellar magnitude of the video camera system was around +11 per field.

\section{Data and analysis}

In the first run in London Ontario (Canada), we detected a total of 17 meteors in almost $18 \mathrm{~h}$, where 13 were simultaneous on both cameras. In the second run in October 2007, 35 meteors in $49 \mathrm{~h}$ were detected and among them, 29 were simultaneously seen on both stations. We examined data for each simultaneous meteor, took the time the event occurred and checked if the meteor ended on the field of view of at least one of the two stations. The end of the trail is particularly critical, since most of the deceleration occurs at the end of a meteor's trajectory. We add to this criterion the requirement that the event should start in the field of view of at least one station as this gives a complete lightcurve for better estimation of the photometric mass of the meteor.

Most of the meteors, as seen from both sites, either started in the field of view but ended outside, or started outside and ended

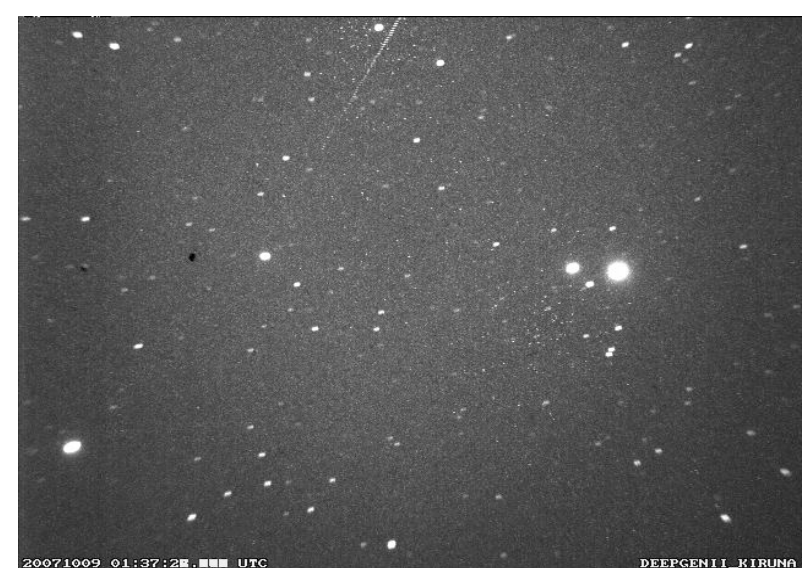

Fig. 2. Meteor captured in Kiruna (Sweden) on October 092007 at 01:37:25 UTC.

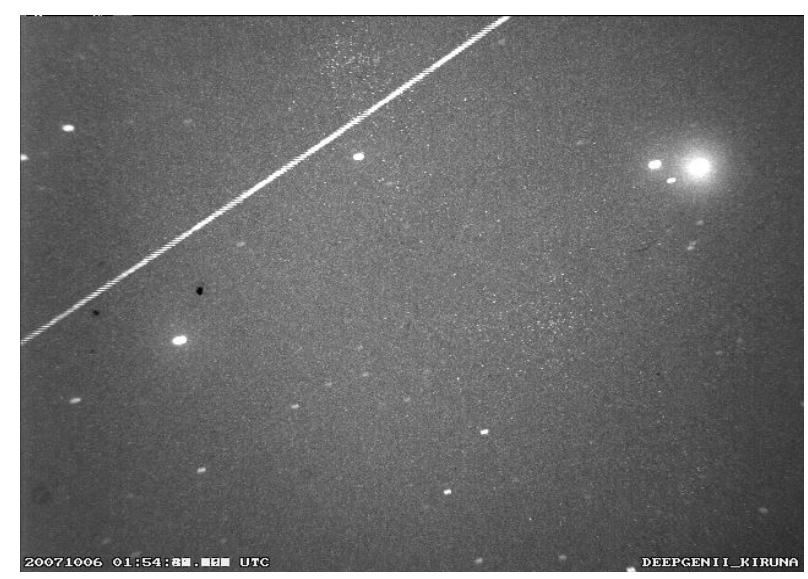

Fig. 3. Meteor captured in Kiruna (Sweden) on October 062007 at 01:54:42 UTC crossing the entire field of view.

in the field of view of one camera (Figs. 1 and 2). Some completely crossed the field of view (Fig. 3). Some even crossed the entire field of view in just one frame, making it virtually impossible to get an astrometric solution. All these meteors failed to satisfy our two criteria and were eliminated. Among the 13 meteors seen simultaneously on both sites in the first observing run, only four satisfied the conditions of starting and ending in the field of view of at least one of the two cameras. From the second observing run, with the narrow field of view and the long baseline between the two stations, only two of the 29 simultaneous meteors satisfied the criteria and were selected.

The astrometric positions of meteors are calibrated using the stars in the field of view. The pixel locations of the stars are found using a centre-of-mass algorithm, and are compared against the SKY2000v4 catalogue (Myers et al. 2001). The right ascension and declination are converted into local zenith and azimuth angles (the camera is fixed to that reference frame). A third order linear least squares fit is used; however, in order to fit a frame close to or including the zenith, rotation is used to rereference each point so that no singularities occur. All of the star coordinates are referenced about the centre of the frame. After this, they are projected onto an xy plane, and then fitted against the pixel locations. While a second order fit may be adequate, a third order fit allows for better lens distortion corrections. Errors in the resulting fit are calculated based on the angular separation between the catalogue and fitted coordinates, so that each star has a single error associated with it. This is more meaningful 


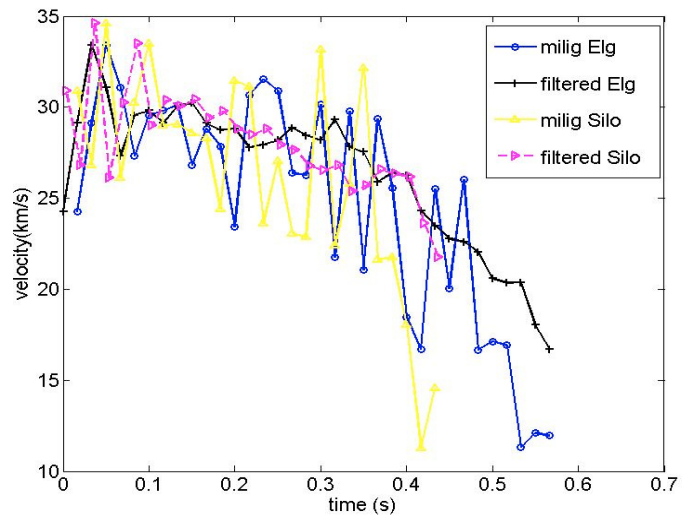

Fig. 4. An example showing the velocity of a meteor before and after the filtering (smoothing) technique.

than quoting separate errors for azimuth and zenith angles, since azimuth error is dependent on the zenith angle. On the GenII systems used in this study, typical errors of 0.002 degrees are found, which corresponds according to our resolution to $\sim 0.3$ pixels.

The meteor positions are manually measured by selecting a point on the leading edge of the meteor. We find that selecting positions manually will result in errors (due to lack of sub-pixel precision) of order 1-2 pixels; this is the dominant source of error in our measurements.

After each frame has been flat fielded, the photometric magnitudes are computed by a log-sum-pixel approach with background subtraction (cf. Hawkes 2002). That is, each star has a defined disc covering the whole star and a surrounding ring representing the background. The median value in the ring is subtracted from the disc (taking into account pixel areas), and the magnitude of the star is computed as the logarithm of the sum of the pixel intensities in the disc. A typical error of 0.1-0.2 mag is found for each star. For all the stars in the image, a linear fit relates these magnitudes against catalogue visual magnitudes (from SKY2000v4 Myers et al. 2001). Because the magnitude base is fixed, the slope value of this fit is fixed at unity, and the offset determines the calibration.

The photometric mass is found using the standard integral of the lightcurve (cf. Hawkes 2002, for details). Here we use value for the luminous efficiency related to velocity from the study by Hill (Hill et al. 2005).

Photometric errors are determined using standard error techniques, where the standard deviation of the photon count is governed by Poisson statistics. This gives an error in the photometric magnitude of $2.5 / \sqrt{N}$ (where $N$ is the pixel intensity sum, proportional to the number of photons), to which the error from the photometric calibration is added.

We used code from Borovička (1990) called Milig to compute the in-atmosphere trajectory of all simultaneous meteors, providing the distance, the velocity and also the height of the meteor versus time along the trajectory. Once the trajectory line has been identified, the velocity can be computed from each station for each pair of points on the trajectory. Small errors in the determined position of the meteor in each frame will produce large random errors on the velocity at each point. In order to reduce this noise on the measurement of velocity versus time (or height), we use a filtering technique which consists of calculating the speed using every third or fourth point instead of every point in the original measurements (Fig. 4). The meteor clearly

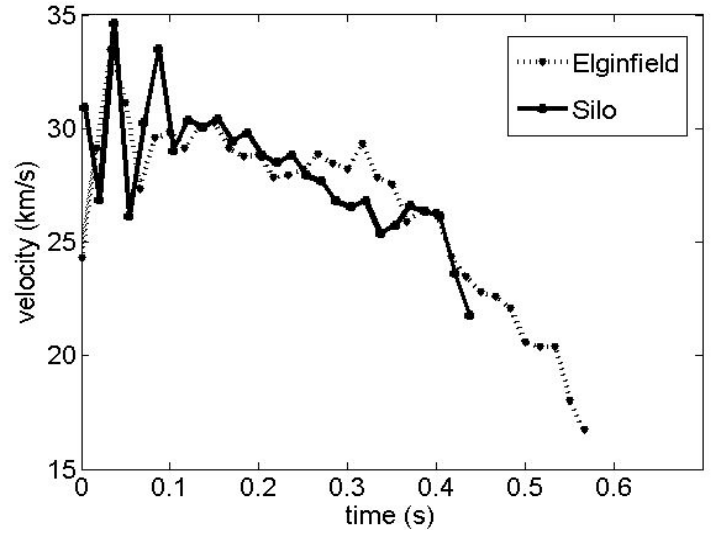

Fig. 5. The velocity of meteor ELSL11 as measured from both sites along its trajectory.

shows deceleration (Fig. 5) and the good agreement between the velocities from each site indicates the solution is robust.

To find the approximate initial, out-of-atmosphere velocity, which is needed as initial input into our model, we make use of the fact that the image resolution of our systems is similar to that of the super-schmidt photographic meteors. Following Whipple \& Jacchia (1957) the pre-atmospheric velocity of the meteoroid was computed following the empirical expression he suggested relating distance $(D)$ to time $(t)$ (Eq. (1)).

$D=A+B t+C \mathrm{e}^{k t}$

The velocity at any time can be found from the time derivative of the expression, Eq. (2). The pre-atmospheric velocity can be found by evaluating the expression with $t$ set to minus infinity. The second derivative of Eq. (1) gives the deceleration, and $k$ is the slope of the logarithm of the deceleration. When $k$ is known, $B$ and $C$ can be determined by the method of least squares. The velocity approaches the pre-atmospheric velocity asymptotically as $t$ approaches minus infinity; the error in the fit can be estimated from the error in the fit parameter (Fig. 6).

$\frac{\mathrm{d} D}{\mathrm{~d} t}=B+C k \mathrm{e}^{k t}$

From the positional measurements at each station, the preatmospheric velocity and the radiant were computed according to Borovička (1990), while the heliocentric meteoroid orbits were computed using the methods of Ceplecha (1987). We note that, due to the geometry used, the meteors captured during the Swedish campaign have relatively greater uncertainty in their solutions due the fact of having only a few measured points for the entire trajectory.

\section{Ablation model}

In our work, we use the dustball model of Campbell-Brown \& Koschny (2004). Where the traditional dustball model suggests that the light production starts as soon as the small grains are all released, the heating of the meteoroid, modeled through Clausius-Clapeyron formalism by Campbell-Brown and Koschny, allows one to consider ablation even before the boiling temperature is reached. The dustball model of Campbell-Brown and Koschny allows the user to enter any number of grains and their masses, without necessarily assuming a power law distribution. This is a considerable advantage, since the computing 


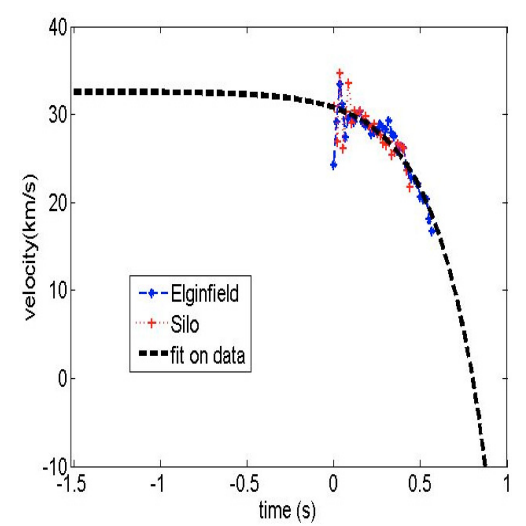

Fig. 6. Velocity of meteor ELSL11 from both sites along its trajectory.

time may be reduced significantly by representing a distribution of grain sizes as a small number of distinct sizes.

The model considers three sources of energy: energy imparted to the meteoroid by collisions with atmospheric atoms, the energy lost from the meteoroid by radiation, and the energy lost through evaporation of the meteor material. The mass loss is calculated using the Knudsen-Langmuir formula, combined with the Clausius-Clapeyron equation. A term proportional to kinetic energy transfer, like the classical formula, is also added to simulate spallation when the meteoroid is very hot. For more details the ablation model itself, see Campbell-Brown \& Koschny (2004).

\section{Results}

For each meteor, we extracted the velocity and the radiant using the trajectory code of Borovička (1990). We extracted the lightcurve of each of the six meteors with complete lightcurves. No correction for photometric saturation was needed since none of these six meteors were bright enough to have any saturated pixels. We applied our ablation model to simultaneously fit the observed lightcurve and deceleration.

Among the parameters used in the model, we have chosen some to remain fixed and some to remain free. Fixed parameters include the fusion point of the meteoroid grains, which is taken to be $100 \mathrm{~K}$ less than the boiling point of the meteoroid grains (the boiling temperature remains free); the condensation coefficient $\psi$, which is fixed to 0.5 (condensation coefficient of stone), the emissivity of the meteoroid (fixed to 0.9), and the atmospheric density, provided by the MSISE 90 model (Hedin 1991).

To fit the observed decelerations and lightcurves, using the model output we search the entire free parameter space for each meteor. This first stage in the solution procedure helps to identify the regions in which solutions are concentrated. The main difficulty with this approach is the grain distribution; while the number of solutions covering a reasonable range of each of the other free parameters is merely prohibitive, the number of possible grain distributions is essentially infinite. As a first approximation, we have chosen to represent each meteor at this step as a collection of grains all having the same size. For each meteoroid, we chose masses of grains (from the smallest grains which will still ablate independently to the total meteoroid mass), and fixed the number of those grains so that the total mass of the meteoroid corresponded to the total photometric mass of the meteor. The shape of the lightcurves found in this way will almost certainly be wrong, but as we get close to a good solution, we expect one of the grain sizes will produce a curve with significant overlap to the measured lightcurve.

We extract from each solution set the best model fit, which we define here to mean the one with the smallest $\chi^{2}$ value (the $\chi^{2}$ here is the standard one where the smallest number indicates the best fit). We allow the theoretical lightcurve and the measured lightcurve to have one fourth of points which do not overlap to within the measured error margins. At this stage, for each of these potential solutions, we adjust the mass and number of grains by hand in order to find the best fit to the observed lightcurve and deceleration.

\subsection{Free parameters}

The free parameters used in our ablation model include:

- grain mass (to which the number of grains is tied);

- density of the meteoroid;

- the heat of ablation $\left(T_{\mathrm{lim}}\right)$;

- the boiling point of the meteoroid grains $\left(T_{\text {boil }}\right)$;

- the temperature at which the grains are released;

- the specific heat $\left(C_{p}\right)$;

- the average molar mass of meteoroid material;

- the thermal conductivity of the meteoroid.

Our methodology is as follows:

First, we allow the density to vary from $500 \mathrm{~kg} \mathrm{~m}^{-3}$ (very porous carbonaceous materials) to $8000 \mathrm{~kg} \mathrm{~m}^{-3}$ (iron meteoroid). We used seven steps in the density. The heat of ablation is of the order of $10^{6} \mathrm{~J} \mathrm{~kg}^{-1}$ (cf. Ceplecha et al. 1998). The actual value depends on the composition of the meteoroid. Babadzhanov (2002) used $2.8 \times 10^{5} \mathrm{~J} \mathrm{~kg}^{-1}$ while Bellot Rubio et al. (2002) thought that it should be around $8 \times 10^{6} \mathrm{~J} \mathrm{~kg}^{-1}$. Following Bellot Rubio et al. (2002), we allow the heat of ablation to range from $2 \times 10^{6}$ to $9 \times 10^{6} \mathrm{~J} \mathrm{~kg}^{-1}$.

Physically, the fragmentation temperature $\left(T_{\text {lim }}\right)$ must be less than the boiling temperature $\left(T_{\text {boil }}\right)$, otherwise the grains will ablate before they separate. Knowing that iron (the densest element we expect to encounter as a major element in the composition of the meteoroid) reaches its boiling temperature around $2000 \mathrm{~K}$, we choose fragmentation temperatures ranging from $900 \mathrm{~K}$ to $1600 \mathrm{~K}$, and set the boiling temperature to vary between $1400 \mathrm{~K}$ to $2300 \mathrm{~K}$.

The thermal conductivity is expected to be small considering the physics of small meteoroids with considerable porosity (Campbell-Brown \& Koschny 2004; Popova 2005). We choose it to range between 0.1 to $1.0 \mathrm{~W} / \mathrm{m} \mathrm{K}$.

We varied the molar mass from 20 to 56 atomic mass units (amu), covering atoms ranging from sodium to iron. We find that most solutions were not very sensitive to molar mass changes if the value was over $36 \mathrm{amu}$. The range of specific heat goes from $600 \mathrm{~J} / \mathrm{kg} \mathrm{K}$ to $1400 \mathrm{~J} / \mathrm{kg} \mathrm{K}$, which correspond to the values used by Campbell-Brown \& Koschny (2004).

In some ablation models, $\Gamma$ (drag coefficient) and $\Lambda$ (heat transfer coefficient) are assumed from the beginning. Examining the Draconids, Borovička et al. (2007) set $\Gamma$ and $\Lambda$ to 1 . Fisher et al. (2000) assumed also $\Gamma$ and $\Lambda=1$. Campbell-Brown $\&$ Koschny (2004) assumed $\Gamma=1$ and $\Lambda=0.5$. In our work, when doing the huge search of solutions, we left $\Gamma$ and $\Lambda$ to be 1 following these earlier studies. After finding the regions near the best solutions, we adjusted them in concert with the mass to improve the model fits. At this stage in our solution procedure, we allow $\Gamma$ and $\Lambda$ to vary from $0.7-0.9$.

To demonstrate our procedure in detail we take meteor ELSL11 as a first example, showing explicitly how we evaluated 
Table 1. Initial grain mass distributions used for meteor ELSL11 in the first stage of analysis.

\begin{tabular}{lll}
\hline \hline Number of size bins & Number of grains & $\begin{array}{l}\text { Grain mass } \\
(\mathrm{kg})\end{array}$ \\
\hline 1 & 121078 & $1.02 \times 10^{-12}$ \\
1 & 60837 & $2.03 \times 10^{-12}$ \\
1 & 9216 & $1.34 \times 10^{-11}$ \\
1 & 7395 & $1.67 \times 10^{-11}$ \\
1 & 693 & $1.78 \times 10^{-10}$ \\
1 & 93 & $1.32 \times 10^{-9}$ \\
\hline
\end{tabular}

the interval of possible values for each parameter. Other meteor events will be discussed only briefly.

\subsection{Evaluation of density}

\subsubsection{Case study of meteor ELSL11}

We start with the observed lightcurve and deceleration (plot of velocity versus height) of meteor ELSL11. The investigation will consist of finding all the modeled lightcurves and decelerations which will match the observed curves. The solution will combine the eight free parameters described above with those which have been fixed (air density, emissivity, etc.). A reasonable determination of each parameter is defined.

It is relatively easy to choose a range of values for each parameter, except for the grain mass. This fact will lead us to approach the real meteoroid grain mass distribution through two steps. We know that the reasonable number of grains in a meteoroid is in the thousands, and the mass of individual grains could range from $10^{-12} \mathrm{~kg}$ (approximately the smallest size which will ablate) to $10^{-8} \mathrm{~kg}$ (about one tenth the total mass for our sample events). The number of sizes of grains involved for any meteoroid is almost certainly more than one; however, in the first step, we consider the meteoroid to be composed of only one size of grain, the mass of which we can alter from $10^{-12} \mathrm{~kg}$ to $10^{-9} \mathrm{~kg}$.

For meteor ELSL11, we present the grain mass distributions which were initially modeled in Table 1 . The photometric mass was taken to be the initial mass. Considering the grain mass ranging from $10^{-9} \mathrm{~kg}$ to $10^{-12}$, we divided the initial photometric mass to have the number of grains. Our goal is to find those grain mass distributions which offer good fits between the modeled lightcurve and deceleration curve, and the observed curves. The second step will then be to use these solutions as starting points and to refine these solutions by finding a grain mass distribution which produces a good fit for the meteor event as defined by the $\chi^{2}$ fit between the model and the observations. For ELSL11, the values of other parameters used in the modelling are given in Table 2.

Using every combination of all these values of the free parameters, we generated 151200 different theoretical lightcurves and decelerations. Each was then compared to the observed ones through the goodness-of-fit using standard $\chi^{2}$. A perfect fit to both curves would have a $\chi^{2}$ value equal to zero.

We sorted these 151200 solutions by the $\chi^{2}$ values, as compared to both the observed lightcurve and the observed deceleration curve. For this event, we rejected any solution with $\chi^{2}$ less than 0.016 . This value is chosen by noting that for this particular event the number of degrees of freedom is 51 and the average sigma (error bar) on the lightcurve is 0.15 mag. As such, this value for the $\chi^{2}$ produces a statistically significant difference between the model and observed lightcurve values (cf.
Bevington \& Robinson 2003). We ended up with two major concentrations of solutions: one around a density of $1000 \mathrm{~kg} \mathrm{~m}^{-3}$ and another around a density of $8000 \mathrm{~kg} \mathrm{~m}^{-3}$.

For each group of solutions, we find the one with the smallest $\chi^{2}$. In our example, the first group of solutions, with densities concentrated around $1000 \mathrm{~kg} \mathrm{~m}^{-3}$, has the best solution at model number 107935 with grain mass $1.78 \mathrm{E}-10 \mathrm{~kg}$, heat of ablation 7.0E6 J/kg, fragmentation temperature $1700 \mathrm{~K}$, boiling temperature $2000 \mathrm{~K}$, specific heat $800 \mathrm{~J} / \mathrm{kg} \mathrm{K}$, molar mass 30 atomic units, and thermal conductivity $1.0 \mathrm{~W} / \mathrm{m} \mathrm{K}$. The second set of solutions around $8000 \mathrm{~kg} \mathrm{~m}^{-3}$ has a grain mass bigger than the one for the low density solution $(1.32 \mathrm{E}-09 \mathrm{~kg})$. The heat of ablation is the same, the fragmentation temperature differs by just $100 \mathrm{~K}$, as does the boiling temperature. The specific heat is the same for both solutions. The best molar mass is 36 atomic units for the $8000 \mathrm{~kg} \mathrm{~m}^{-3}$ solution, compared to 30 atomic units for the low density solution. For the thermal conductivity, the best value for the $8000 \mathrm{~kg} \mathrm{~m}^{-3}$ solution is half that of the $1000 \mathrm{~kg} \mathrm{~m}^{-3}$ solution.

In examining the modelled lightcurves and velocity profiles for the two best solutions (a low density solution around $1000 \mathrm{~kg} \mathrm{~m}^{-3}$ and high density solution around $8000 \mathrm{~kg} \mathrm{~m}^{-3}$ ) we find that the high density solution matches the observed data better than the low density solution. The low density solution shows the light production stopping at $87 \mathrm{~km}$; the observed data go down to $83 \mathrm{~km}$. Figures 7 and 8 show the lightcurves of the high and low density solutions; Figs. 9 and 10 show the decelerations for the two solutions.

The next step in our solution procedure is to use these two best model fits as starting points, and to refine the grain masses, heat transfer and drag coefficients to find the best possible solution in the phase space region. This step was done by hand, adding and subtracting grains of different masses while keeping the other parameters constant. At each step, both the lightcurve and deceleration produced by the model were compared to the observed curves.

The starting values of the parameters for the high density solution were those of the best fit, listed in the previous section. The shape of the lightcurve is clearly not single body, meaning that more than one size of grain is needed to model it properly. We attempted to find a better solution using three different grain masses. We were able to find a model which is very close to the observed data (Figs. 11 and 12). The parameters for this fit are given in Table 3.

For the low density solution, we began by modifying the number and size of the grains involved. As with the high density solution, we used three grain sizes. The initial attempt used the same parameters as the single grain size model, but had 450 grains with masses of $1.10 \times 10^{-11} \mathrm{~kg}, 430$ grains with a mass of $1.35 \times 10^{-10} \mathrm{~kg}$, and 30 grains with a mass of $1.93 \times 10^{-9} \mathrm{~kg}$. The peak magnitude produced by this model was too small, so we then increased the mass of the grains in the middle bin from $1.35 \times 10^{-10} \mathrm{~kg}$ to $2.35 \times 10^{-10} \mathrm{~kg}$. This matched the maximum magnitude, but the model produced more light than observed at higher and lower altitudes, and did not penetrate as far into the atmosphere as the observed meteor. To correct for the latter, we increased the mass of the largest grains to $2.53 \times 10^{-9} \mathrm{~kg}$. The lightcurve for this model is compared to the observed lightcurve in Fig. 13; the parameters used are given in Table 4.

In all three of the solutions where grain numbers and masses were varied, the model solution reaches the detection threshold earlier than the observed lightcurve. This could be corrected if the fragmentation temperature is increased, releasing the grains just prior to the height where the meteor becomes visible. In 
Table 2. Values for the parameters (other than grain mass) used in the modelling. $T_{\text {lim }}$ is the temperature at which fragmentation occurs, $T_{\text {boil }}$ the boiling point of the grains, $C_{\mathrm{p}}$ the specific heat, Mmass the molar mass, and Thermal Cond the thermal conductivity of the bulk meteoroid (Meteor ELSL11).

\begin{tabular}{lllllll}
\hline \hline $\begin{array}{l}\text { Density } \\
\left(\mathrm{kg} \mathrm{m}^{-3}\right)\end{array}$ & $\begin{array}{l}\text { Heat of ablation } \\
\left(\mathrm{J} \mathrm{kg}^{-1}\right)\end{array}$ & $\begin{array}{l}T_{\text {lim }} \\
(\mathrm{K})\end{array}$ & $\begin{array}{l}T_{\text {boil }} \\
(\mathrm{K})\end{array}$ & $\begin{array}{l}C_{\mathrm{p}} \\
(\mathrm{J} / \mathrm{kg} \mathrm{K})\end{array}$ & $\begin{array}{l}\text { Mmass } \\
(\mathrm{amu})\end{array}$ & $\begin{array}{l}\text { Thermal Cond } \\
(\mathrm{W} / \mathrm{m} \mathrm{K})\end{array}$ \\
\hline 500 & $2 \mathrm{E} 6$ & 900 & 1500 & 800 & 20 & 0.2 \\
1000 & $4 \mathrm{E} 6$ & 1200 & 1700 & 1000 & 30 & 0.5 \\
2000 & $5 \mathrm{E} 6$ & 1350 & 1800 & 1200 & 36 & 0.7 \\
4000 & $7 \mathrm{E} 6$ & 1600 & 2000 & & & 1.0 \\
6000 & & & & & & \\
7500 & & & & & & \\
8000 & & & & & &
\end{tabular}

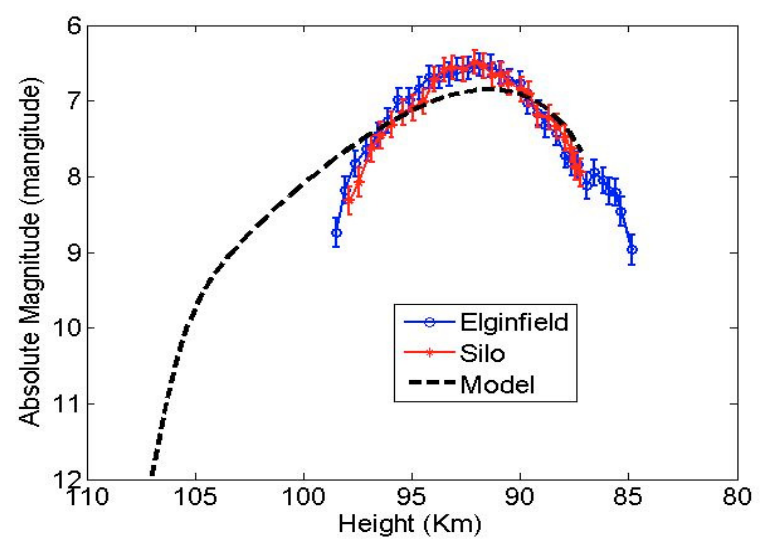

Fig. 7. Lightcurve of the best single grain mass solution around $1000 \mathrm{~kg} \mathrm{~m}^{3}$.

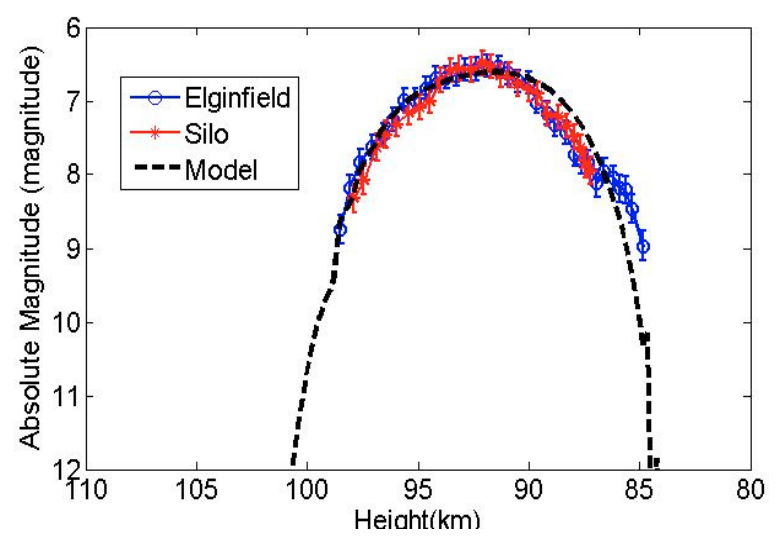

Fig. 8. Lightcurve of the best single grain mass solution around $8000 \mathrm{~kg} \mathrm{~m}^{3}$ for ELSL11.

order to match the observed starting height, it was necessary to raise the fragmentation temperature from $1700 \mathrm{~K}$ to $3000 \mathrm{~K}$. In order to keep the fragmentation temperature lower than the boiling temperature, we also had to raise the boiling temperature to $3300 \mathrm{~K}$, and we set the fusion temperature to $3200 \mathrm{~K}$ for consistency. We used the same grain mass distribution as in the previous solution. The parameters for this modified solution are given in Table 5, and the model is compared to the observed lightcurve in Fig. 14.

The solution around $1000 \mathrm{~kg} \mathrm{~m}^{-3}$ is still a poor fit, and it seems physically unrealistic to have a low density meteoroid with a fragmentation temperature as high as $3000 \mathrm{~K}$. We therefore reject the low density solution, and proceed to refine the

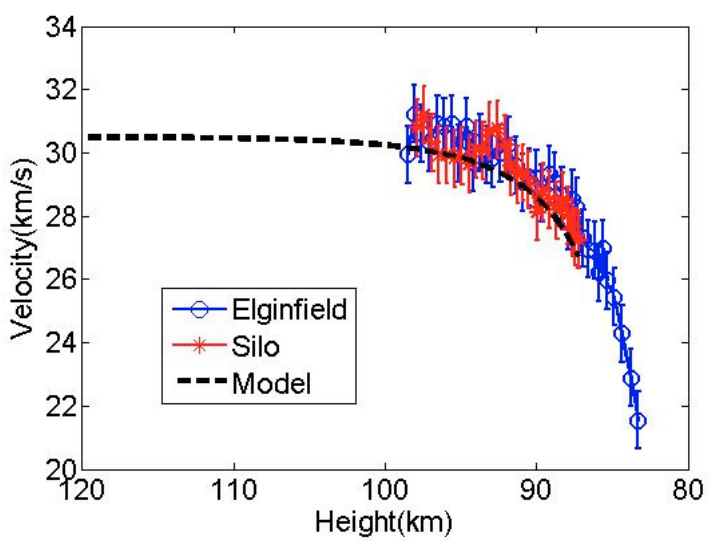

Fig. 9. Deceleration of the best single grain mass solution around $1000 \mathrm{~kg} \mathrm{~m}^{3}$ for ELSL11.

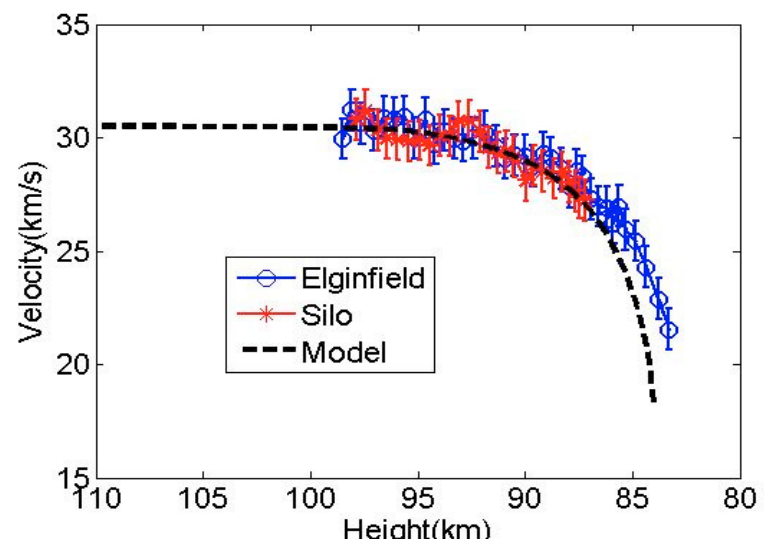

Fig. 10. Deceleration of the best single grain mass solution around $8000 \mathrm{~kg} \mathrm{~m}^{3}$ for ELSL11.

density measurement assuming that the meteoroid's density is close to $8000 \mathrm{~kg} \mathrm{~m}^{-3}$.

The point of the first search over the eight different parameters is to identify broadly the different regions where the possible solutions fall, to work on the best solution from each region, to determine where among all the different concentrations of solutions the best solution lies, and determine the likely mass distribution of the grains in the meteoroid. We will now fix the grain distribution, and perform a second search with greater resolution in the density parameter, which is the parameter of greatest interest to us. We allow the other parameters (apart from grain masses) to vary as shown in Table 6. 
Table 3. Table summarizing parameters involved in the final stage of the high density solution model for ELSL11. Den is density, Qf is heat of ablation, Cps is specific heat, Thermal Cond is thermal conductivity.

\begin{tabular}{lllllllll}
\hline \hline \# grains & $\begin{array}{l}\text { Grain mass } \\
(\mathrm{kg})\end{array}$ & $\begin{array}{l}\text { Den } \\
\mathrm{kg} \mathrm{m}^{-3}\end{array}$ & $\begin{array}{l}\text { Qf } \\
\left(\mathrm{J} \mathrm{kg}^{-1}\right)\end{array}$ & $\begin{array}{l}T_{\text {lim }} \\
(\mathrm{K})\end{array}$ & $\begin{array}{l}T_{\text {boil }} \\
(\mathrm{K})\end{array}$ & $\begin{array}{l}\text { Cps } \\
(\mathrm{J} / \mathrm{kg} \mathrm{K})\end{array}$ & $\begin{array}{l}\text { Molar mass } \\
\mathrm{au}\end{array}$ & $\begin{array}{l}\text { Thermal Cond. } \\
\mathrm{W} / \mathrm{m} \mathrm{K}\end{array}$ \\
\hline 450 & $1.10 \mathrm{E}-11$ & & & & & & & \\
430 & $1.35 \mathrm{E}-10$ & 8000 & 7000000 & 1600 & 2100 & 800 & 36 & 0.5 \\
30 & $1.993 \mathrm{E}-09$ & & & & & & & \\
\hline
\end{tabular}

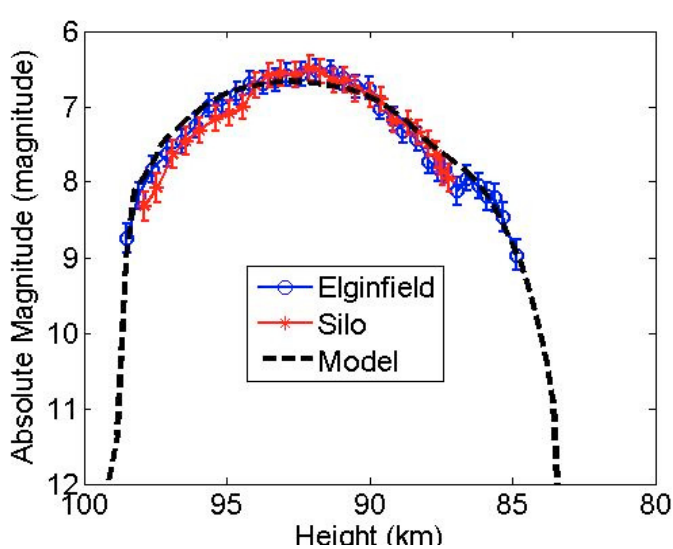

Fig. 11. Lightcurve for ELSL11 with the model fit for a density of $8000 \mathrm{~kg} \mathrm{~m}^{-3}$ using parameters from Table 3 .

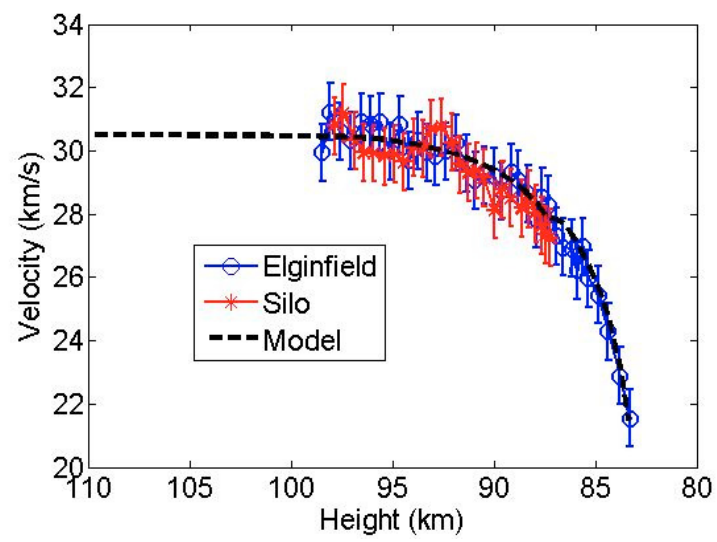

Fig. 12. Deceleration for ELSL11 for a density of $8000 \mathrm{~kg} \mathrm{~m}^{-3}$ using parameters from Table 3.

Using every possible combination of the parameters in the table, we computed 432000 modeled solutions. We compared each of these to the observed lightcurves and deceleration of ELSL11. For this search, we set a stricter limit on the $\chi^{2}$ value of 0.08 for both the lightcurve and deceleration comparison; this roughly corresponds to a solution which fits inside the error bars of both plots. We ended up with 234 different good solutions (solutions with $\chi^{2}$ less than or equal to our limit) with densities from $5000 \mathrm{~kg} \mathrm{~m}^{-3}$ to $8000 \mathrm{~kg} \mathrm{~m}^{-3}$ for ELSL11. The greatest number of good solutions falls between a density of $5500 \mathrm{~kg} \mathrm{~m}^{-3}$ and $6500 \mathrm{~kg} \mathrm{~m}^{-3}$. Among these 234 solutions, the best one (with the smallest $\chi^{2}$ both on the lightcurve and the deceleration) has a density of $5500 \mathrm{~kg} \mathrm{~m}^{-3}$ with a total mass of $1.36 \times 10^{-7} \mathrm{~kg}$. All other parameters associated with this particular solution are summarized in Table 7 .

To determine the range of probable densities in our final model fits, we adopt the best fit value and expressed

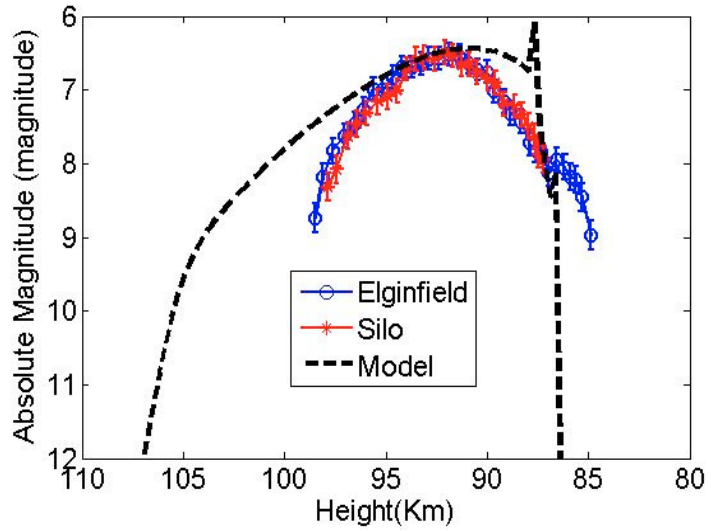

Fig. 13. Modified solution for $1000 \mathrm{~kg} \mathrm{~m}^{-3}$ using three grain masses. The sudden jump in the predicted light output from the model indicates a sudden fragmentation event.

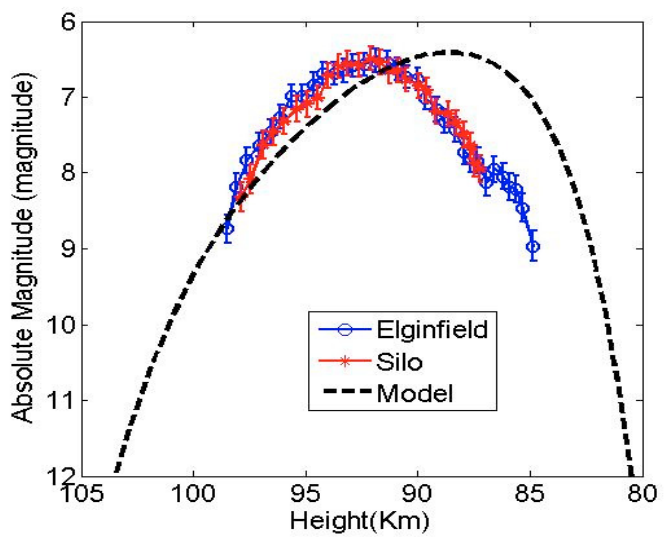

Fig. 14. Modified solution for $1000 \mathrm{~kg} \mathrm{~m}^{-3}$, with three grain sizes and modified temperatures of fragmentation, boiling and fusion.

the density of ELSL11 by an asymmetrical error bar as $5500+2500 /-500 \mathrm{~kg} \mathrm{~m}^{-3}$, expressing the full range of possible density fits for our chosen $\chi^{2}$ cut.

This detailed example serves to outline our methodology as we try to fit our model to the available metric and photometric observations. In the next sections, we will briefly summarize our findings for the additional 5 meteor events for which we were able to apply this detailed approach.

\subsubsection{Meteor ELSL01}

Using the mass distribution in Table 8, we modeled a 352800 combinations of the free parameters, with densities concentrated around 7000 and $8000 \mathrm{~kg} \mathrm{~m}^{-3}$. For this event, statistically significance required the solutions to have a $\chi^{2}$ less than or equal to 0.078 on the lightcurve and less than or equal to 0.1 on 
Table 4. Distribution of grains for the solution around $1000 \mathrm{~kg} \mathrm{~m}^{-3}$ using three grain masses.

\begin{tabular}{lllllllll}
\hline \hline \# grains & $\begin{array}{l}\text { Grain mass } \\
(\mathrm{kg})\end{array}$ & $\begin{array}{l}\text { Den } \\
\left(\mathrm{kg} \mathrm{m}^{-3}\right)\end{array}$ & $\begin{array}{l}\text { Qf } \\
\left(\mathrm{J} \mathrm{kg}^{-1}\right)\end{array}$ & $\begin{array}{l}T_{\text {lim }} \\
(\mathrm{K})\end{array}$ & $\begin{array}{l}T_{\text {boil }} \\
(\mathrm{K})\end{array}$ & $\begin{array}{l}\text { Cps } \\
(\mathrm{J} / \mathrm{kg} \mathrm{K})\end{array}$ & $\begin{array}{l}\text { Molar mass } \\
(\mathrm{au})\end{array}$ & $\begin{array}{l}\text { Thermal Cond. } \\
(\mathrm{W} / \mathrm{m} \mathrm{K})\end{array}$ \\
\hline 450 & $1.10 \mathrm{E}-11$ & & & & & & & \\
430 & $2.35 \mathrm{E}-10$ & 1000 & 7000000 & 1700 & 2000 & 800 & 30 & 1 \\
30 & $2.53 \mathrm{E}-09$ & & & & & & & \\
\hline
\end{tabular}

Table 5. Distribution of grains for the solution around $1000 \mathrm{~kg} \mathrm{~m}^{-3}$, with three grain sizes and modified temperatures of fragmentation, boiling and fusion.

\begin{tabular}{lllllllll}
\hline \hline \# grains & $\begin{array}{l}\text { Grain mass } \\
(\mathrm{kg})\end{array}$ & $\begin{array}{l}\text { Den } \\
\left(\mathrm{kg} \mathrm{m}^{-3}\right)\end{array}$ & $\begin{array}{l}\text { Qf } \\
\left(\mathrm{J} \mathrm{kg}^{-1}\right)\end{array}$ & $\begin{array}{l}T_{\text {lim }} \\
(\mathrm{K})\end{array}$ & $\begin{array}{l}T_{\text {boil }} \\
(\mathrm{K})\end{array}$ & $\begin{array}{l}\text { Cps } \\
(\mathrm{J} / \mathrm{kg} \mathrm{K})\end{array}$ & $\begin{array}{l}\text { Molar mass } \\
(\mathrm{au})\end{array}$ & $\begin{array}{l}\text { Thermal Cond. } \\
(\mathrm{W} / \mathrm{m} \mathrm{K})\end{array}$ \\
\hline 450 & $1.10 \mathrm{E}-11$ & & & & & & & \\
430 & $2.35 \mathrm{E}-10$ & 1000 & 7000000 & 3000 & 3300 & 800 & 30 & 1 \\
30 & $2.53 \mathrm{E}-09$ & & & & & & & \\
\hline
\end{tabular}

Table 6. Variation of parameters used modeling lightcurves and decelerations for ELSL11 in the second stage search. The mass column does not give the variation of grain sizes, but the actual grain distribution used in every model.

\begin{tabular}{cccccccc}
\hline \hline $\begin{array}{c}\text { Mass } \\
(\mathrm{kg})\end{array}$ & $\begin{array}{c}\text { Density } \\
\left(\mathrm{kg} \mathrm{m}^{-3}\right)\end{array}$ & $\begin{array}{c}\text { Heat of Abl } \\
\left(\mathrm{J} \mathrm{kg}^{-1}\right)\end{array}$ & $\begin{array}{c}T_{\text {lim }} \\
(\mathrm{K})\end{array}$ & $\begin{array}{c}T_{\text {boil }} \\
(\mathrm{K})\end{array}$ & $\begin{array}{c}\text { Specific heat } \\
(\mathrm{J} / \mathrm{kg} \mathrm{K})\end{array}$ & $\begin{array}{c}\text { Molar mass } \\
(\mathrm{au})\end{array}$ & $\begin{array}{c}\text { Thermal conduc } \\
(\mathrm{W} / \mathrm{m} \mathrm{K})\end{array}$ \\
\hline $450 \times 1.10 \times 10^{-11}$ & 3500 & $5 \times 10^{6}$ & 900 & 1800 & 700 & 20 & 0.2 \\
$430 \times 1.35 \times 10^{-10}$ & 4000 & $6 \times 10^{6}$ & 1000 & 1900 & 800 & 30 & 0.3 \\
$30 \times 1.93 \times 10^{-09}$ & 4500 & $7 \times 10^{6}$ & 1100 & 2000 & 900 & 36 & 0.5 \\
& 5000 & $8 \times 10^{6}$ & 1200 & 2100 & 1000 & 56 & 0.7 \\
& 5500 & $9 \times 10^{6}$ & 1400 & 2200 & 1100 & & \\
& 6000 & & 1450 & 2300 & 1200 & & \\
& 6500 & & 1500 & & & & \\
& 7000 & & 1550 & & & & \\
& 7500 & & 1600 & & & & \\
& 8000 & & 1800 & & & & \\
& 8500 & & & & & & \\
& & & & & & & \\
\hline
\end{tabular}

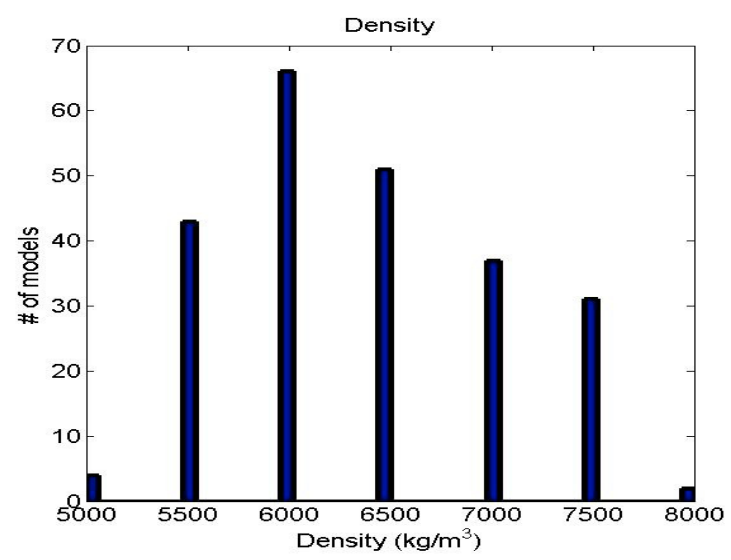

Fig. 15. Plot of the best density solutions for ELSL11. The best solution falls at $5500 \mathrm{~kg} \mathrm{~m}^{-3}$. The left bound is $5000 \mathrm{~kg} \mathrm{~m}^{-3}$ and the right bound is $8000 \mathrm{~kg} \mathrm{~m}^{-3}$.

deceleration; a total of 167 solutions matched the observed data (Fig. 17). Among these solutions, the best one has a density of $7000 \mathrm{~kg} \mathrm{~m}^{-3}$ (plotted in Fig. 18); the values of the other parameters are given in Table 9. The total mass of ELSL01, which had a velocity of $11.3 \mathrm{~km} \mathrm{~s}^{-1}$, close to the earth escape velocity, was modeled to be $4.36 \times 10^{-6} \mathrm{~kg}$. The density of ELSL01 was found to be $7000+1500 /-1500 \mathrm{~kg} \mathrm{~m}^{-3}$.

\subsubsection{Meteor ELSL09}

Using the grain mass distribution in Table 8, we computed 483000 solutions with density ranging from $250 \mathrm{~kg} \mathrm{~m}^{-3}$ to $3000 \mathrm{~kg} \mathrm{~m}^{-3}$. We found 147 solutions whose lightcurves and decelerations matched the observed ones with a statistically significant value of standard $\chi^{2}$ of better than 0.06 on both lightcurve and deceleration (Fig. 19). Among these good solutions, the one having the smallest standard chi-square had a density of $900 \mathrm{~kg} \mathrm{~m}^{-3}$ (Fig. 20) with a total modeled mass of $7.63 \times 10^{-8} \mathrm{~kg}$. Values of the other parameters for this particular solution are summarized in Table 9. The best fit density for ELSL09 is $900+250 /-150 \mathrm{~kg} \mathrm{~m}^{-3}$.

\subsubsection{Meteor ELSL12}

With the grain mass distribution in Table 8, we effected a search to find a more precise determination of the density which was computed using a standard $\chi^{2}$ cutoff of 0.15 or less on the lightcurve and 0.1 on the deceleration. This left 753 solutions and gives the density distribution shown in Fig. 21. Among all of these solutions, the best one had a density of $4500 \mathrm{~kg} \mathrm{~m}^{-3}$ (shown in Fig. 22) with a total modeled mass of $4.41 \times 10^{-8} \mathrm{~kg}$. The values of the other parameters in the best model are specified in Table 9. The density of ELSL12 was found to be $4500+2000 /-2500 \mathrm{~kg} \mathrm{~m}^{-3}$. 
Table 7. Values of parameters producing the best model solution among 234 solutions found to describe meteor ELSL11.

\begin{tabular}{cccccccc}
\hline \hline $\begin{array}{c}\text { Mass } \\
(\mathrm{kg})\end{array}$ & $\begin{array}{c}\text { Density } \\
\left(\mathrm{kg} \mathrm{m}^{-3}\right)\end{array}$ & $\begin{array}{c}\text { Heat of abl } \\
\left(\mathrm{J} \mathrm{kg}^{-1}\right)\end{array}$ & $\begin{array}{c}T_{\text {lim }} \\
(\mathrm{K})\end{array}$ & $\begin{array}{c}T_{\text {boil }} \\
(\mathrm{K})\end{array}$ & $\begin{array}{c}\text { Specific heat } \\
(\mathrm{J} / \mathrm{kg} \mathrm{K})\end{array}$ & $\begin{array}{c}\text { Molar mass } \\
(\mathrm{au})\end{array}$ & $\begin{array}{c}\text { Thermal conduc } \\
(\mathrm{W} / \mathrm{m} \mathrm{K})\end{array}$ \\
\hline $\begin{array}{c}450 \times 1.10 \times 10^{-11} \\
430 \times 1.3 \times 10^{-10}\end{array}$ & 5500 & $8 \times 10^{6}$ & 1400 & 2300 & 1100 & 36 & 0.5 \\
$30 \times 1.93 \times 10^{-9}$ & & & & & & & \\
\hline
\end{tabular}

Table 8. Summary table for the six meteors modelled in detail in this study. A value of 1 under the size column means there is only one size of grains used in the modelling, 1, 2 two sizes in the composition of the meteoroid and 1, 2, 3 three sizes of grains in the composition of the meteoroid.

\begin{tabular}{|c|c|c|c|c|c|c|c|c|c|c|c|}
\hline Name & $\begin{array}{c}\text { Modeled mass } \\
(\mathrm{kg})\end{array}$ & $\begin{array}{c}\text { Grain mass } \\
(\mathrm{kg})\end{array}$ & \# grains & $\overline{\text { Size }}$ & $\begin{array}{c}\text { Dens } \\
\left(\mathrm{kg} \mathrm{m}^{-3}\right)\end{array}$ & $\begin{array}{c}\mathrm{Qf} \\
\left(\mathrm{J} \mathrm{kg}^{-1}\right)\end{array}$ & $\begin{array}{l}T_{\lim } \\
(\mathrm{K})\end{array}$ & $\begin{array}{l}T_{\text {boil }} \\
(\mathrm{K})\end{array}$ & $\begin{array}{c}C_{p} \\
(\mathrm{~J} / \mathrm{Kg} \mathrm{K}) \\
\end{array}$ & $\begin{array}{c}\text { Mmass } \\
(\mathrm{au})\end{array}$ & $\begin{array}{l}\text { Ther Cond } \\
(\mathrm{W} / \mathrm{m} \mathrm{K})\end{array}$ \\
\hline ELSL01 & $4.36 \times 10^{-7}$ & $\begin{array}{l}1.50 \times 10^{-10} \\
4.50 \times 10^{-9}\end{array}$ & $\begin{array}{c}3550 \\
470\end{array}$ & $\begin{array}{l}1 \\
2\end{array}$ & 7200 & $5 \times 10^{6}$ & 1500 & 2100 & 1000 & 36 & 0.2 \\
\hline ELSL09 & $7.63 \times 10^{-8}$ & $\begin{array}{l}1.0 \times 10^{-11} \\
9.7 \times 10^{-10}\end{array}$ & $\begin{array}{c}8 \\
87\end{array}$ & $\begin{array}{l}1 \\
2\end{array}$ & 900 & $5 \times 10^{6}$ & 1400 & 2100 & 1100 & 30 & 0.3 \\
\hline ELSL11 & $1.36 \times 10^{-7}$ & $\begin{array}{c}1.10 \times 10^{-11} \\
1.3 \times 10^{-10} \\
1.93 \times 10^{-9}\end{array}$ & $\begin{array}{c}450 \\
430 \\
30\end{array}$ & $\begin{array}{l}1 \\
2 \\
3\end{array}$ & 5500 & $8 \times 10^{6}$ & 1400 & 2300 & 1100 & 36 & 0.5 \\
\hline ELSL12 & $4.41 \times 10^{-8}$ & $\begin{array}{l}3.16 \times 10^{-11} \\
2.02 \times 10^{-9}\end{array}$ & $\begin{array}{c}900 \\
8\end{array}$ & $\begin{array}{l}1 \\
2\end{array}$ & 4500 & $5 \times 10^{6}$ & 1400 & 2100 & 1200 & 36 & 0.2 \\
\hline $\begin{array}{l}\text { PEKI08 } \\
\text { PEKI09 }\end{array}$ & $\begin{array}{l}1.40 \times 10^{-7} \\
1.77 \times 10^{-7}\end{array}$ & $\begin{array}{l}1.78 \times 10^{-10} \\
1.78 \times 10^{-10}\end{array}$ & $\begin{array}{l}787 \\
998\end{array}$ & $\begin{array}{l}1 \\
1\end{array}$ & $\begin{array}{l}600 \\
500\end{array}$ & $\begin{array}{l}7 \times 10^{6} \\
9 \times 10^{6}\end{array}$ & $\begin{array}{l}1300 \\
1200\end{array}$ & $\begin{array}{l}2200 \\
2300\end{array}$ & $\begin{array}{l}1300 \\
1200\end{array}$ & $\begin{array}{l}36 \\
20\end{array}$ & $\begin{array}{l}0.7 \\
0.2\end{array}$ \\
\hline
\end{tabular}

Table 9. Summary table of the six meteors and their statistical densities as given by the method. A value of 1 in the size column means there is only one size of grains in the composition of the meteoroid, 1, 2 two sizes in the composition of the meteoroid and $1,2,3$ three sizes of grains in the composition of the meteoroid.

\begin{tabular}{|c|c|c|c|c|c|}
\hline Name & $\begin{array}{l}\text { Modeled mass } \\
(\mathrm{kg})\end{array}$ & $\begin{array}{c}\text { Grain mass } \\
(\mathrm{kg})\end{array}$ & \# grains & size & $\begin{array}{c}\text { density } \\
\left(\mathrm{kg} \mathrm{m}^{-3}\right)\end{array}$ \\
\hline ELSL01 & $4.36 \times 10^{-6}$ & $\begin{array}{l}1.50 \times 10^{-10} \\
4.50 \times 10^{-9}\end{array}$ & $\begin{array}{c}3550 \\
470\end{array}$ & $\begin{array}{l}1 \\
2\end{array}$ & $7000+1500 /-1500$ \\
\hline ELSL09 & $7.63 \times 10^{-8}$ & $\begin{array}{l}1.0 \times 10^{-11} \\
9.7 \times 10^{-10}\end{array}$ & $\begin{array}{c}8 \\
87\end{array}$ & $\begin{array}{l}1 \\
2\end{array}$ & $900+200 /-250$ \\
\hline ELSL11 & $1.36 \times 10^{-7}$ & $\begin{array}{c}1.10 \times 10^{-11} \\
1.3 \times 10^{-10} \\
1.93 \times 10^{-9}\end{array}$ & $\begin{array}{c}450 \\
430 \\
30\end{array}$ & $\begin{array}{l}1 \\
2 \\
3\end{array}$ & $5500+2500 /-500$ \\
\hline ELSL12 & $4.41 \times 10^{-8}$ & $\begin{array}{l}3.16 \times 10^{-11} \\
2.02 \times 10^{-9}\end{array}$ & $\begin{array}{c}900 \\
8\end{array}$ & $\begin{array}{l}1 \\
2\end{array}$ & $4500+2000 /-2500$ \\
\hline $\begin{array}{l}\text { PEKI08 } \\
\text { PEKI09 }\end{array}$ & $\begin{array}{l}1.40 \times 10^{-7} \\
1.77 \times 10^{-7}\end{array}$ & $\begin{array}{l}1.78 \times 10^{-10} \\
1.78 \times 10^{-10}\end{array}$ & $\begin{array}{l}787 \\
998\end{array}$ & $\begin{array}{l}1 \\
1\end{array}$ & $\begin{array}{l}600+200 /-200 \\
500+300 /-300\end{array}$ \\
\hline
\end{tabular}

Table 10. Sumary table for the first observing campaign near London Ontario (Canada). Hb is beginning height, Hi is initial height (actual height as appeared on the field of view), He is ending height and Hf is final height (actual height as appeared on the field of view). The velocity is the no-atmosphere velocity computed as outlined in the text.

\begin{tabular}{|c|c|c|c|c|c|c|c|}
\hline \multirow[t]{2}{*}{ Name } & \multirow[t]{2}{*}{ Date } & \multirow[t]{2}{*}{ Time (UTC) } & \multirow[t]{2}{*}{ Velocity $\left(\mathrm{km} \mathrm{s}^{-1}\right)$} & \multicolumn{4}{|c|}{ Positions on FOV } \\
\hline & & & & $\mathrm{Hb}(\mathrm{km})$ & $\mathrm{Hi}(\mathrm{km})$ & He (km) & Hf (km) \\
\hline ELSL01 & 20040517 & 04:56:04 & $11.3 \pm 0.9$ & 81.91 & 81.9 & 77.2 & 77.2 \\
\hline ELSL02 & 20040517 & $06: 35: 18$ & $31.8 \pm 0.7$ & & 102.1 & & 98.2 \\
\hline ELSL03 & 20040520 & $05: 46: 48$ & $17.7 \pm 1.2$ & & 95.5 & & 81.7 \\
\hline ELSL04 & 20040520 & 08:01:42 & $31.7 \pm 1.1$ & & 97.5 & & 97.4 \\
\hline ELSL05 & 20040527 & $05: 10: 42$ & $11.6 \pm 1.5$ & & 80.2 & 76.6 & 76.6 \\
\hline ELSL06 & 20040527 & $05: 30: 38$ & $35.6 \pm 0.9$ & & 102.6 & & 97.9 \\
\hline ELSL07 & 20040527 & $06: 05: 21$ & $14.5 \pm 1.3$ & & 89.4 & 85.6 & 85.6 \\
\hline ELSL08 & 20040527 & $06: 42: 38$ & $14.8 \pm 0.8$ & 95.8 & 95.8 & & 91.2 \\
\hline ELSL09 & 20040527 & $07: 35: 40$ & $30.3 \pm 0.9$ & 100.5 & 100.5 & 93.4 & 93.4 \\
\hline ELSL10 & 20040527 & $07: 51: 43$ & $24.3 \pm 1.2$ & 89.2 & 89.2 & & 84.7 \\
\hline ELSL11 & 20040527 & $08: 19: 27$ & $30.5 \pm 0.8$ & 98.5 & 98.5 & 83.3 & 83.3 \\
\hline ELSL12 & 20040527 & $08: 32: 51$ & $31.6 \pm 0.9$ & 101.1 & 101.1 & 90.9 & 90.9 \\
\hline ELSL13 & 20040527 & 08:33:42 & $31.1 \pm 1.3$ & & 98.3 & & 93.5 \\
\hline
\end{tabular}



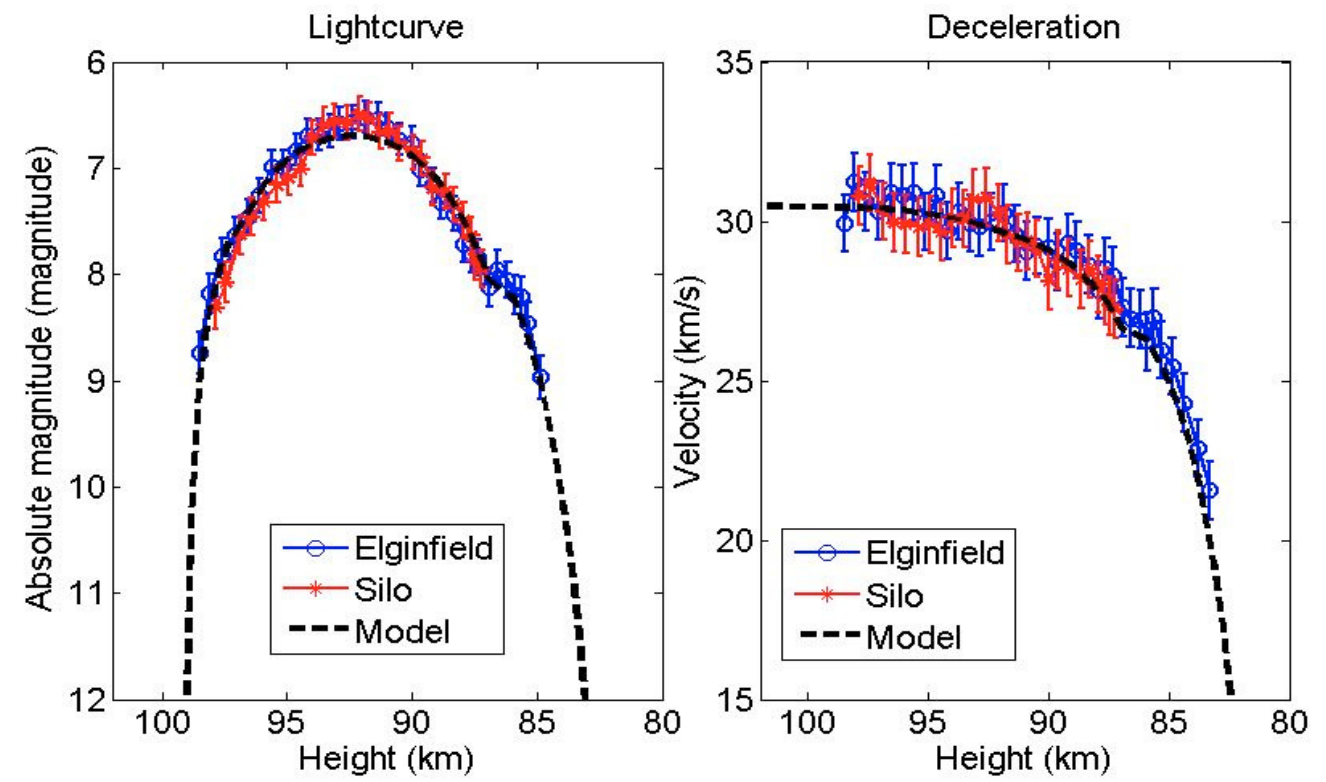

Fig. 16. The best model of meteor ELSL11, with a density of $5500 \mathrm{~kg} \mathrm{~m}^{-3}$.

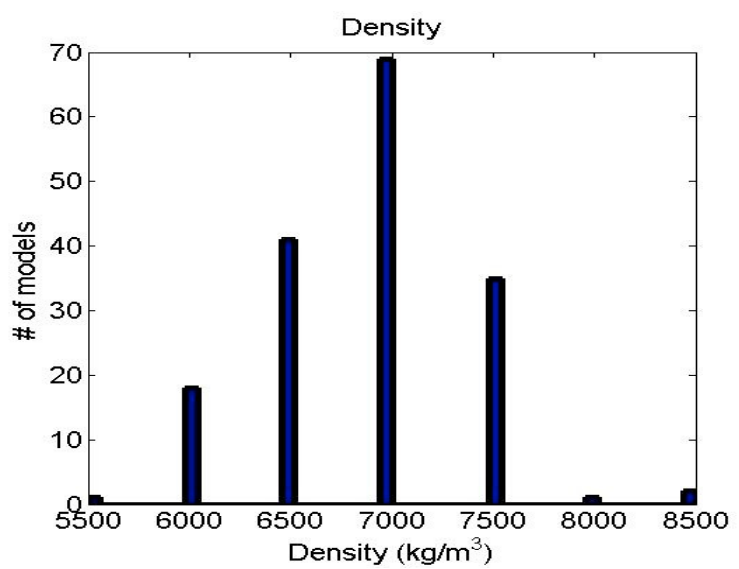

Fig. 17. Plot of accepted solutions for ELSL01. The best solution falls at $7000 \mathrm{~kg} \mathrm{~m}^{-3}$. The left bound is $5500 \mathrm{~kg} \mathrm{~m}^{-3}$ and the right bound is $8500 \mathrm{~kg} \mathrm{~m}^{-3}$.

\subsubsection{Meteor PEKI08}

The second search was based on 330750 different models using the grain mass distribution in Table 8. The modeled densities ranged from $200 \mathrm{~kg} \mathrm{~m}^{-3}$ to $1200 \mathrm{~kg} \mathrm{~m}^{-3}$. Only models having a standard $\chi^{2}$ less than or equal to 0.04 on the lightcurve and 0.01 on the deceleration were considered. 1525 solutions satisfied the conditions, shown in Fig. 23. Among them, the best one had a density of $600 \mathrm{~kg} \mathrm{~m}^{-3}$ (Fig. 24) with a total modeled mass of $1.40 \times 10^{-7} \mathrm{~kg}$. Other parameter values are given in Table 9. The density of PEKI 08 was found to be $600+200 /-200 \mathrm{~kg} \mathrm{~m}^{-3}$.

\subsubsection{Meteor PEKI09}

Using the mass distribution in Table 8 and the resolution on the density parameter from $200 \mathrm{~kg} \mathrm{~m}^{-3}$ to $1500 \mathrm{~kg} \mathrm{~m}^{-3}$ with a step of $50 \mathrm{~kg} \mathrm{~m}^{-3}, 330000$ model solutions were computed. These were required to have a standard $\chi^{2}$ on lightcurve and deceleration less than or equal to 0.07. A total number of 2994 solutions satisfied this particular condition, and the density distribution is plotted in Fig. 25. Among these good solutions, the best one had a density of $500 \mathrm{~kg} \mathrm{~m}^{-3}$ (plotted in Fig. 26) and its total modeled mass was $1.77 \times 10^{-7} \mathrm{~kg}$. Table 9 shows the values of other parameters of the best solution. The good solutions range from $200 \mathrm{~kg} \mathrm{~m}^{-3}$ to $800 \mathrm{~kg} \mathrm{~m}^{-3}$ and the best solution with the smallest $\chi^{2}$ is $500 \mathrm{~kg} \mathrm{~m}^{-3}$. The density of PEKI09 is estimated as $500+300 /-300 \mathrm{~kg} \mathrm{~m}^{-3}$.

\section{Discussion}

Our analysis emphasizes that when it comes to modeling meteoroid behaviour, where many free parameters are involved, we should not in general expect to find a unique solution matching the lightcurve, or even both the lightcurve and the deceleration. Different combinations of free parameters can produce modeled lightcurves and decelerations falling within the observed error bars. If solutions closely matching the observations can be found for both high and low densities, the data often are not sufficiently restrictive to uniquely determine the meteoroid density. We found, for the six meteors we observed, that good solutions were concentrated in a relatively small portion of the density space, meaning that a meaningful density and an estimate of the error could be found. In our case, the fact that the number of good fits falls to zero for densities higher and lower than the best fit density gives the ultimate boundaries to the meteoroid density, though these may be somewhat conservative.

Our analysis revealed similar behaviour to that found by Borovicka et al. (2007). Both works showed that meteoroids fragment gradually near the onset of detectable light production into constituent grains whose masses vary in a very narrow range between $10^{-9}$ and $10^{-12}$. In both studies, the disruption occurs with an energy around $10^{6} \mathrm{~J} \mathrm{~kg}^{-1}$. The grain distribution used in our study (between one and three discrete sizes of grain) is in contrast to that used in other studies, many of which use the more physical assumption of a power law (Borovicka et al. 2007; Beech 1986; Beech \& Murray 2003). The lightcurves produced by this simplification are almost as smooth as the power-law generated curves, and deliver a considerable gain in computation time, since particles of the same size released at the same time can be simulated as a single particle and their luminosity later 

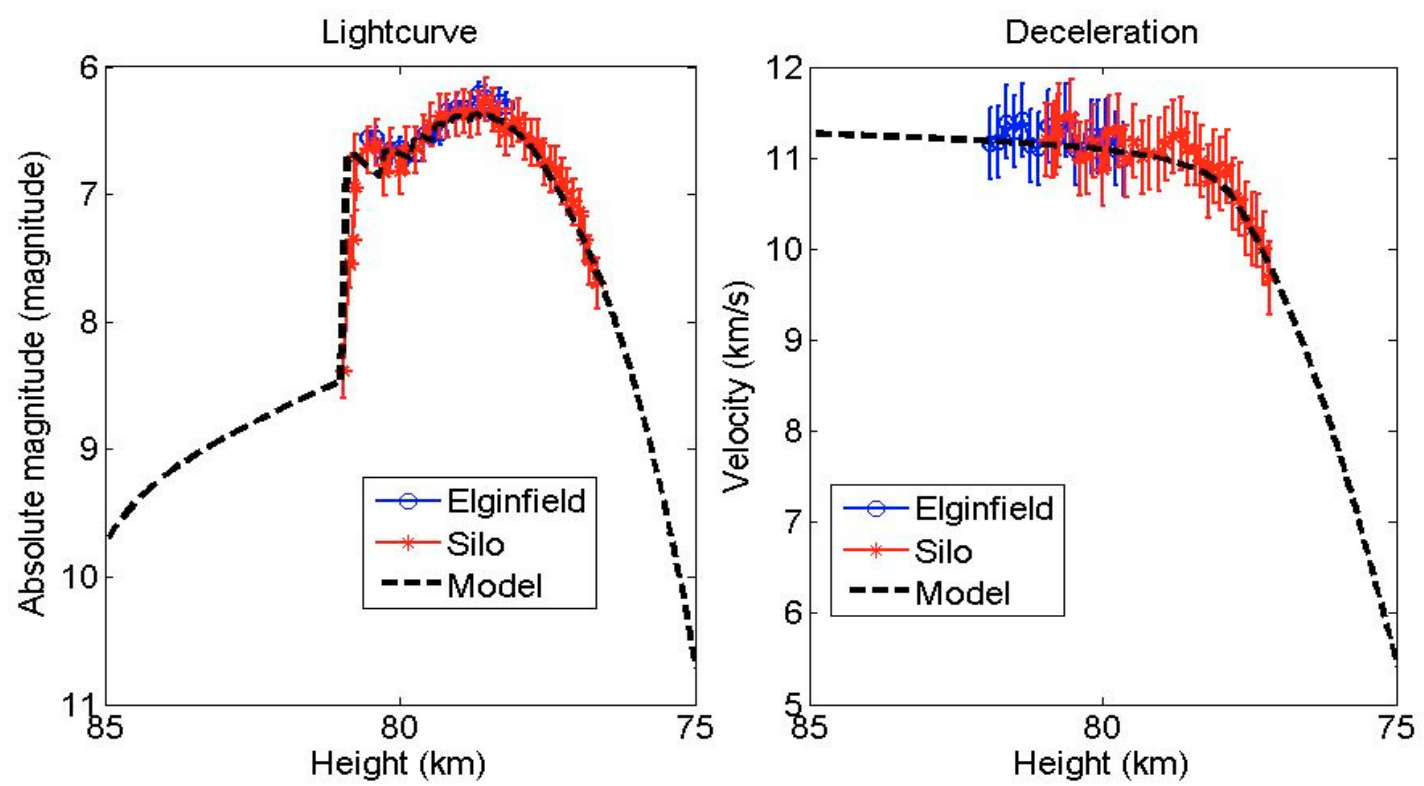

Fig. 18. Lightcurve and deceleration of ELSL01, with best model.

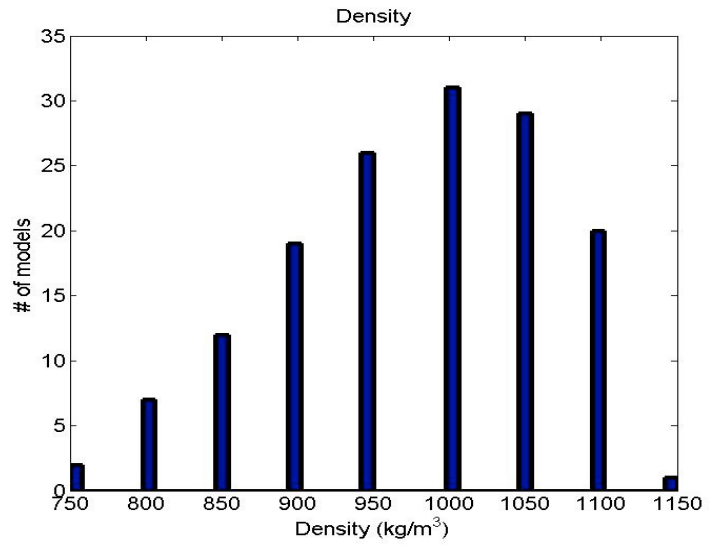

Fig. 19. Plot of best solutions for ELSL09.The best solution falls at $900 \mathrm{~kg} \mathrm{~m}^{-3}$. The left bound is $750 \mathrm{~kg} \mathrm{~m}^{-3}$ and the right bound is $1150 \mathrm{~kg} \mathrm{~m}^{-3}$.

multiplied. Computation time was of critical importance in our study, since hundreds of thousands of models had to be run for each meteor.

In this work, we obtained the density of each meteoroid after fitting both its lightcurve and deceleration. This was done for first time by Borovicka et al. (2007) for six Draconids. They found an estimated density of $300 \mathrm{~kg} \mathrm{~m}^{-3}$ for Draconids in full agreement with Ceplecha (1988) and Revelle (2001). The meteoroids in our work had a range of densities going from $500 \mathrm{~kg} \mathrm{~m}^{-3}$ to $7000 \mathrm{~kg} \mathrm{~m}^{-3}$, overlapping with values obtained by Babadzhanov (2002) and Bellot Rubio et al. (2002).

Three of the six meteoroids have very high density (ELSL01, ELSL11, ELSL12). They fall well within the range of density defined by Babazhanov (2002) whose investigation on density of meteoroids took into account the fragmentation process. But they are significantly higher than the range defined by Bellot Rubio et al. (2002). Some of the ablation for these higher density meteoroids may be occurring as liquid droplets, rather than as discrete grains (Lebedinets \& Portnyagin 1968). Association of these high density meteoroids with asteroidal objects is further supported by their orbits which have tisserand values greater than 3 , consistent with an asteroidal origin. These events may represent the iron meteoroid population identified at slightly larger sizes spectrally by Borovicka et al. (2005); our work suggests that this iron meteoroid population may extend down to even smaller masses. Among the meteors we believe underwent fragmentation (and had more than one size of grain), ELSL09 does have a low density. Thus, we cannot automatically associate fragmentation with high values of density. This suggests that when the model is based not only on the observed lightcurve, but also on the observed deceleration behaviour of the meteoroid, there is no exclusive bias against finding low densities with the model. We can also address the disagreement of Bellot Rubio et al. (2002) with Babazhanov's work (Babazhanov 2002) concerning the value of heat of ablation. Babazhanov (2002) assumed the heat of ablation to be fixed to $2.8 \times 10^{5} \mathrm{~J} \mathrm{~kg}^{-1}$ (latter, he brought it to $2 \times 10^{6} \mathrm{~J} \mathrm{~kg}^{-1}$ ), but in our study we found different heats of ablation involved in good model fits of different meteoroids. This shows that the heat of ablation cannot be assumed, but should be fitted as a free parameter. The density of three other meteoroids (ELSL09, PEKI08, PEKI09) fell well inside both the ranges defined by Bellot Rubio et al. (2002) and Babazhanov (2002). All of these meteors fragmented, but had densities at the lower end.

The heights of meteors of the Swedish campaign (at different season and latitude) are significantly higher than the Canadian one. This is partly the result of the observing geometry and may also reflect our detection bias given the volume sampled from both sites. While one of our six events has a nominally hyperbolic orbit, the precision of the velocity measurement (given the paucity of data points for the Swedish campaign data) together with the large extrapolation between the observed and extraatmosphere velocity suggests to us rather that this is measurement uncertainty.

\section{Conclusion}

In this work we have, for the first time for meteoroids in the size range of $10^{-7}$ to $10^{-8} \mathrm{~kg}$, used both the dynamic and photometric observations of meteoroids to determine their densities, 

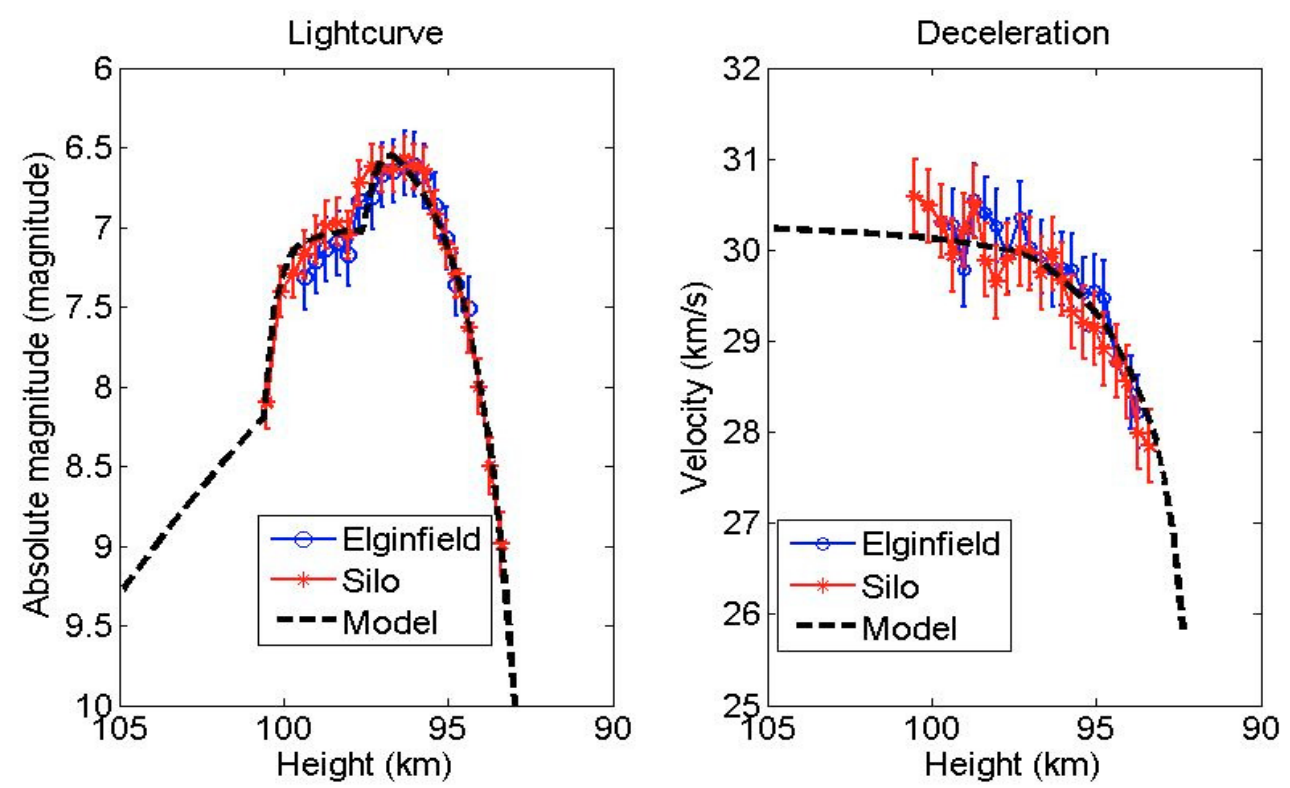

Fig. 20. Lightcurve and deceleration of ELSL09 together with the best model fit.

Table 11. Summary table of the second observing campaign from Kiruna (Sweden) and Peera (Finland). Hb is beginning height, Hi is initial height (actual height as appeared on the field of view), He is ending height and Hf is final height (actual height as appeared on the field of view). The velocity is the no-atmosphere velocity computed as outlined in the text.

\begin{tabular}{|c|c|c|c|c|c|c|c|}
\hline \multirow[t]{2}{*}{ Name } & \multirow[t]{2}{*}{ Date } & \multirow[t]{2}{*}{ Time (UTC) } & \multirow[t]{2}{*}{ Velocity $\left(\mathrm{km} \mathrm{s}^{-1}\right)$} & \multicolumn{4}{|c|}{ Positions on FOV } \\
\hline & & & & $\mathrm{Hb}(\mathrm{km})$ & Hi $(\mathrm{km})$ & $\mathrm{He}(\mathrm{km})$ & Hf $(\mathrm{km})$ \\
\hline PEKI01 & 20071006 & $01: 54: 42$ & $63.7 \pm 1.6$ & & 105.4 & & 102.6 \\
\hline PEKI02 & 20071008 & $20: 45: 52$ & $14.9 \pm 0.9$ & & 92.6 & & 88.1 \\
\hline PEKI03 & 20071008 & $22: 17: 01$ & $28.9 \pm 1.2$ & & 100.7 & & 96.7 \\
\hline PEKI04 & 20071008 & $23: 08: 30$ & $38.4 \pm 1.2$ & & 106.1 & 96.3 & 96.3 \\
\hline PEKI05 & 20071009 & $01: 36: 48$ & $59.6 \pm 1.4$ & & 101.1 & & 97.1 \\
\hline PEKI06 & 20071009 & $01: 37: 25$ & $50.8 \pm 0.9$ & & 105.5 & 97.8 & 97.8 \\
\hline PEKI07 & 20071009 & $01: 45: 58$ & $34.3 \pm 1.3$ & 103.1 & 103.1 & & 91.7 \\
\hline PEKI08 & 20071009 & $01: 49: 48$ & $46.9 \pm 0.8$ & 107.4 & 107.4 & 98.2 & 98.2 \\
\hline PEKI09 & 20071009 & $01: 55: 13$ & $67.9 \pm 0.9$ & 112.0 & 112.0 & 98.6 & 98.6 \\
\hline PEKI10 & 20071009 & $02: 32: 20$ & $60.8 \pm 1.3$ & & 108.7 & & 102.4 \\
\hline PEKI11 & 20071010 & 01:03:45 & $57.7 \pm 0.9$ & & 104.1 & 93.5 & 93.5 \\
\hline PEKI12 & 20071010 & $01: 47: 22$ & $26.7 \pm 0.7$ & & 99.7 & & 93.7 \\
\hline PEKI13 & 20071010 & $01: 49: 10$ & $31.3 \pm 1.6$ & & 99.9 & & 91.5 \\
\hline PEKI14 & 20071010 & $21: 30: 38$ & $41.2 \pm 0.8$ & & 103.3 & & 95.3 \\
\hline PEKI15 & 20071010 & $21: 45: 44$ & $38.4 \pm 0.9$ & & 104.3 & 93.7 & 93.7 \\
\hline PEKI16 & 20071010 & 22:07:01 & $62.4 \pm 1.3$ & & 109.2 & & 101.4 \\
\hline PEKI17 & 20071010 & $22: 33: 32$ & $35.7 \pm 0.8$ & & 101.5 & & 87.5 \\
\hline PEKI18 & 20071010 & $22: 51: 37$ & $23.6 \pm 1.2$ & 99.9 & 99.9 & & 91.6 \\
\hline PEKI19 & 20071010 & 23:03:20 & $29.2 \pm 0.9$ & 101.7 & 101.7 & & 96.8 \\
\hline PEKI20 & 20071011 & 01:00:16 & no solution & - & - & - & - \\
\hline PEKI21 & 20071011 & $02: 53: 28$ & $41.3 \pm 1.3$ & 103.5 & 103.5 & & 96.3 \\
\hline PEKI22 & 20071011 & $02: 55: 32$ & $22.5 \pm 0.9$ & 98.9 & 98.9 & & 93.4 \\
\hline PEKI23 & 20071011 & $02: 57: 54$ & $79.7 \pm 1.8$ & & 122.4 & & 108.5 \\
\hline PEKI24 & 20071011 & 03:08:40 & $63.4 \pm 1.2$ & & 106.4 & & 97.6 \\
\hline PEKI25 & 20071012 & $19: 49: 53$ & $34.4 \pm 0.8$ & 104.2 & 104.2 & & 95.9 \\
\hline PEKI26 & 20071012 & $20: 00: 28$ & $26.1 \pm 0.9$ & & 99.9 & & 96.1 \\
\hline PEKI27 & 20071012 & $20: 14: 15$ & $51.3 \pm 1.5$ & & 105.4 & 93.5 & 93.5 \\
\hline PEKI28 & 20071013 & 00:04:16 & $64.5 \pm 1.3$ & & 110.2 & & 96.7 \\
\hline PEKI29 & 20071013 & 00:09:26 & $31.2 \pm 0.9$ & & 100.3 & & 97.7 \\
\hline
\end{tabular}

using a full simulation of ablation including fragmentation. We have exhaustively searched the parameter space to ensure that the density limits we determine from the model fully characterize the possible range of density. Previous studies of meteoroid 
Table 12. Table summarizing orbital elements of all 42 meteors. alp geo and del geo are respectively geocentric right ascension and declination at the epoch J2000.0. TJ is Tisserand parameter with respect to Jupiter. PEKI20 is the case of meteors which crossed the entire field of view making it difficult to compute any trajectory solution.

\begin{tabular}{|c|c|c|c|c|c|c|c|c|c|c|}
\hline \multirow[t]{2}{*}{ Name } & \multicolumn{2}{|c|}{ Radiant } & \multicolumn{7}{|c|}{ Orbital elements } & \multirow[t]{2}{*}{ TJ } \\
\hline & $\alpha_{g}\left({ }^{\circ}\right)$ & $\delta_{g}\left({ }^{\circ}\right)$ & $a(\mathrm{AU})$ & $e$ & $i\left({ }^{\circ}\right)$ & $\omega\left(^{\circ}\right)$ & $\Omega\left(^{\circ}\right)$ & q per $(A U)$ & q aph (AU) & \\
\hline ELSL01 & $214.5 \pm 0.4$ & $1.5 \pm 1.3$ & $1.06 \pm 0.04$ & $0.1 \pm 0.2$ & $1.2 \pm 0.8$ & $47.9 \pm 0.8$ & $236.6 \pm 0.1$ & $0.99 \pm 0.01$ & $1.14 \pm 0.08$ & 5.804 \\
\hline ELSL02 & $257.8 \pm 1.1$ & $-22.1 \pm 1.1$ & $1.3 \pm 0.1$ & $0.84 \pm 0.01$ & $1.4 \pm 1.7$ & $317.5 \pm 1.9$ & $56.66 \pm 0.03$ & $0.21 \pm 0.02$ & $2.4 \pm 0.2$ & 4.542 \\
\hline ELSL03 & $215.0 \pm 1.4$ & $32.4 \pm 1.1$ & $2.9 \pm 0.8$ & $0.7 \pm 0.1$ & $14.7 \pm 1.5$ & $207.9 \pm 1.2$ & $59.5 \pm 0.1$ & $0.965 \pm 0.005$ & $4.8 \pm 1.5$ & 2.825 \\
\hline ELSLO4 & $239.5 \pm 1.4$ & $-43.3 \pm 1.1$ & $4.2 \pm 1.3$ & $0.88 \pm 0.04$ & $23.5 \pm 1.2$ & $94.9 \pm 2.3$ & $239.6 \pm 0.1$ & $0.5 \pm 0.1$ & $7.9 \pm 2.6$ & 2.021 \\
\hline ELSL05 & $179.5 \pm 2.9$ & $25.25 \pm 2.02$ & $2.6 \pm 1.3$ & $0.6 \pm 0.2$ & $1.9 \pm 1.5$ & $181.8 \pm 1.9$ & $66.2 \pm 0.1$ & $1.0 \pm 0.3$ & $4.1 \pm 2.7$ & 3.131 \\
\hline ELSL06 & $260.3 \pm 1.1$ & $-13.3 \pm 1.1$ & $3.6 \pm 0.9$ & $0.92 \pm 0.02$ & $15.2 \pm 1.7$ & $299.2 \pm 2.4$ & $66.2 \pm 0.1$ & $0.29 \pm 0.02$ & $6.8 \pm 1.7$ & 2.074 \\
\hline ELSL07 & $82.76 \pm 2.8$ & $64.8 \pm 4.1$ & $1.3 \pm 0.1$ & $0.32 \pm 0.07$ & $10.9 \pm 3.0$ & $127.4 \pm 4.3$ & $66.241 \pm 0.001$ & $0.918 \pm 0.006$ & $1.8 \pm 0.3$ & 4.930 \\
\hline ELSL08 & $201.3 \pm 3.5$ & $61.8 \pm 1.2$ & $1.7 \pm 0.2$ & $0.42 \pm 0.06$ & $14.2 \pm 1.6$ & $178.5 \pm 1.4$ & $66.3 \pm 0.1$ & $1.01 \pm 0.01$ & $2.5 \pm 0.3$ & 4.064 \\
\hline ELSL09 & $259.6 \pm 1.1$ & $-6.3 \pm 1.1$ & $1.9 \pm 0.2$ & $0.80 \pm 0.02$ & $19.2 \pm 1.4$ & $292.4 \pm 2.4$ & $66.3 \pm 0.1$ & $0.39 \pm 0.02$ & $3.5 \pm 0.4$ & 3.422 \\
\hline ELSL10 & $304.3 \pm 1.1$ & $14.9 \pm 1.1$ & $0.644 \pm 0.007$ & $0.65 \pm 0.02$ & $41.9 \pm 4.1$ & $346.7 \pm 1.1$ & $66.31 \pm 0.01$ & $0.22 \pm 0.01$ & $1.07 \pm 0.01$ & 8.472 \\
\hline ELSL11 & $272.8 \pm 1.4$ & $41.9 \pm 1.1$ & $2.1 \pm 0.2$ & $0.57 \pm 0.05$ & $47.5 \pm 1.2$ & $225.1 \pm 3.1$ & $66.33 \pm 0.01$ & $0.91 \pm 0.01$ & $3.3 \pm 0.5$ & 3.182 \\
\hline ELSL12 & $307.9 \pm 1.5$ & $44.7 \pm 1.1$ & $1.01 \pm 0.05$ & $0.03 \pm 0.02$ & $59.9 \pm 1.7$ & $272.4 \pm 3.1$ & $66.34 \pm 0.01$ & $0.99 \pm 0.05$ & $1.04 \pm 0.05$ & 5.590 \\
\hline ELSL13 & $318.1 \pm 1.1$ & $8.6 \pm 1.1$ & $0.56 \pm 0.06$ & $0.84 \pm 0.02$ & $72.7 \pm 1.4$ & $354.7 \pm 0.7$ & $66.34 \pm 0.01$ & $0.09 \pm 0.01$ & $1.04 \pm 0.01$ & 9.392 \\
\hline PEKI01 & $84.6 \pm 1.1$ & $-3.02 \pm 1.1$ & $8.8 \pm 0.1$ & $0.9 \pm 0.1$ & $129.1 \pm 1.8$ & $55.3 \pm 5.3$ & $12.3 \pm 0.1$ & $0.79 \pm 0.03$ & $16.8 \pm 0.4$ & -0.124 \\
\hline PEKI02 & $326.1 \pm 1.2$ & $-6.3 \pm 2.8$ & $2.6 \pm 0.6$ & $0.64 \pm 0.09$ & $1.8 \pm 0.9$ & $207.5 \pm 1.3$ & $195.1 \pm 0.5$ & $0.9 \pm 0.1$ & $4.3 \pm 1.2$ & 3.086 \\
\hline PEKI03 & $22.9 \pm 1.1$ & $2.3 \pm 1.1$ & $2.6 \pm 0.3$ & $0.83 \pm 0.02$ & $6.67 \pm 1.04$ & $103.2 \pm 2.2$ & $15.148 \pm 0.001$ & $0.44 \pm 0.01$ & $4.8 \pm 0.6$ & -0.287 \\
\hline PEKI04 & $156.7 \pm 2.1$ & $61.5 \pm 1.1$ & $0.99 \pm 0.06$ & $0.35 \pm 0.02$ & $74.9 \pm 2.2$ & $67.9 \pm 9.4$ & $194.4 \pm 0.1$ & $0.64 \pm 0.04$ & $1.33 \pm 0.08$ & 5.466 \\
\hline PEKI05 & $80.6 \pm 1.1$ & $8.7 \pm 1.1$ & $1.8 \pm 0.3$ & $0.75 \pm 0.03$ & $145.9 \pm 2.4$ & $108.3 \pm 6.7$ & $15.3 \pm 0.1$ & $0.44 \pm 0.04$ & $3.1 \pm 0.6$ & 2.244 \\
\hline PEKI06 & $77.2 \pm 1.2$ & $34.6 \pm 1.1$ & $0.88 \pm 0.04$ & $0.79 \pm 0.02$ & $144.2 \pm 2.9$ & $328.3 \pm 2.9$ & $195.3 \pm 0.1$ & $0.2 \pm 0.1$ & $1.6 \pm 0.1$ & 5.499 \\
\hline PEKI07 & $175.7 \pm 2.1$ & $61.01 \pm 1.04$ & $1.1 \pm 0.1$ & $0.4 \pm 0.1$ & $61.6 \pm 2.4$ & $81.7 \pm 4.5$ & $195.3 \pm 0.1$ & $0.69 \pm 0.03$ & $1.5 \pm 0.1$ & 5.128 \\
\hline PEKI08 & $77.98 \pm 1.52$ & $48.43 \pm 0.06$ & $0.85 \pm 0.04$ & $0.65 \pm 0.02$ & $111.7 \pm 2.2$ & $321.1 \pm 3.5$ & $195.3 \pm 0.1$ & $0.30 \pm 0.02$ & $1.41 \pm 0.06$ & 5.890 \\
\hline PEKI09 & $82.5 \pm 1.8$ & $57.2 \pm 1.1$ & $-1.8 \pm 0.3$ & $1.49 \pm 0.09$ & $120.8 \pm 1.5$ & $220.4 \pm 2.6$ & $195.3 \pm 0.1$ & $0.86 \pm 0.02$ & - & -3.554 \\
\hline PEKI10 & $85.9 \pm 1.1$ & $4.59 \pm 1.01$ & $1.9 \pm 0.4$ & $0.67 \pm 0.05$ & $140.6 \pm 2.1$ & $86.9 \pm 7.3$ & $15.3 \pm 0.1$ & $0.62 \pm 0.04$ & $3.1 \pm 0.7$ & 2.043 \\
\hline PEKI11 & $91.5 \pm 1.4$ & $43.7 \pm 1.1$ & $1.19 \pm 0.09$ & $0.45 \pm 0.03$ & $137.6 \pm 1.9$ & $275.6 \pm 7.9$ & $196.3 \pm 0.1$ & $0.66 \pm 0.04$ & $1.7 \pm 0.2$ & 3.739 \\
\hline PEKI12 & $0.1 \pm 1.4$ & $41.6 \pm 1.1$ & $2.5 \pm 0.3$ & $0.73 \pm 0.03$ & $27.3 \pm 1.1$ & $257.8 \pm 2.3$ & $196.3 \pm 0.1$ & $0.66 \pm 0.01$ & $4.3 \pm 0.6$ & 2.922 \\
\hline PEKI13 & $351.9 \pm 3.4$ & $72.45 \pm 1.03$ & $2.0 \pm 0.4$ & $0.6 \pm 0.1$ & $48.9 \pm 2.3$ & $232.6 \pm 4.2$ & $196.3 \pm 0.1$ & $0.86 \pm 0.01$ & $3.15 \pm 0.71$ & 3.252 \\
\hline PEKI14 & $30.6 \pm 1.3$ & $37.9 \pm 1.1$ & $4.4 \pm 1.4$ & $0.94 \pm 0.01$ & $47.8 \pm 1.9$ & $300.4 \pm 2.7$ & $197.09 \pm 0.01$ & $0.27 \pm 0.02$ & $8.6 \pm 2.7$ & 1.603 \\
\hline PEKI15 & $156.3 \pm 2.2$ & $62.16 \pm 1.03$ & $0.96 \pm 0.05$ & $0.30 \pm 0.02$ & $75.7 \pm 1.7$ & $65.8 \pm 9.2$ & $197.1 \pm 0.1$ & $0.67 \pm 0.04$ & $1.26 \pm 0.06$ & 5.619 \\
\hline PEKI16 & $162.5 \pm 1.3$ & $40.07 \pm 1.01$ & $-2.1 \pm 0.6$ & $1.2 \pm 0.1$ & $109.4 \pm 1.9$ & $98.4 \pm 3.7$ & $197.1 \pm 0.1$ & $0.52 \pm 0.03$ & - & -2.756 \\
\hline PEKI17 & $213.1 \pm 3.2$ & $71.35 \pm 1.03$ & $2.8 \pm 0.5$ & $0.6 \pm 0.1$ & $57.7 \pm 1.1$ & $156.8 \pm 2.6$ & $197.1 \pm 0.1$ & $0.97 \pm 0.01$ & \pm 0.9 & 2.484 \\
\hline PEKI18 & $262.89 \pm 2.4$ & $63.9 \pm 1.1$ & $2.1 \pm 0.3$ & $0.5 \pm 0.1$ & $34.4 \pm 1.8$ & $176.1 \pm 1.8$ & $197.1 \pm 0.1$ & $0.9 \pm 0.1$ & $3.2 \pm 0.6$ & 3.384 \\
\hline PEKI19 & $19.02 \pm 1.06$ & $14.76 \pm 1.05$ & $3.2 \pm 0.5$ & $0.86 \pm 0.02$ & $6.28 \pm 1.08$ & $281.4 \pm 2.2$ & $197.150 \pm 0.001$ & $0.45 \pm 0.02$ & $5.9 \pm 0.9$ & -0.814 \\
\hline PEKI20 & - & - & - & - & - & - & - & - & - & - \\
\hline PEKI21 & $200.2 \pm 4.4$ & $76.54 \pm 1.02$ & $5.0 \pm 2.5$ & $0.8 \pm 0.1$ & $67.3 \pm 1.5$ & $166.8 \pm 2.4$ & $197.3 \pm 0.1$ & $0.9 \pm 0.1$ & $9.1 \pm 4.9$ & 1.494 \\
\hline PEKI22 & $309.9 \pm 2.0$ & $58.6 \pm 1.1$ & $2.5 \pm 0.3$ & $0.62 \pm 0.05$ & $29.7 \pm 1.4$ & $206.3 \pm 1.6$ & $197.3 \pm 0.1$ & $0.9 \pm 0.1$ & $4.1 \pm 0.7$ & 3.025 \\
\hline PEKI23 & $99.6 \pm 1.1$ & $23.1 \pm 1.1$ & $-1.3 \pm 0.3$ & $1.7 \pm 0.2$ & $179.9 \pm 0.5$ & $203.9 \pm 5.2$ & $198.1 \pm 5.1$ & $0.95 \pm 0.01$ & - & -5.374 \\
\hline PEKI24 & $127.6 \pm 1.1$ & $25.34 \pm 1.01$ & $1.5 \pm 0.2$ & $0.6 \pm 0.1$ & $167.2 \pm 2.1$ & $93.5 \pm 8.0$ & $197.3 \pm 0.1$ & $0.6 \pm 0.4$ & $2.5 \pm 0.4$ & 2.629 \\
\hline PEKI25 & $176.7 \pm 3.6$ & $73.33 \pm 1.03$ & $1.2 \pm 0.1$ & $0.21 \pm 0.04$ & $62.8 \pm 1.4$ & $134.4 \pm 9.7$ & $198.01 \pm 0.01$ & $0.94 \pm 0.02$ & $1.4 \pm 0.1$ & 4.763 \\
\hline PEKI26 & $31.88 \pm 1.05$ & $8.6 \pm 1.1$ & $1.4 \pm 0.1$ & $0.72 \pm 0.02$ & $3.9 \pm 1.1$ & $117.5 \pm 2.1$ & $19.01 \pm 0.01$ & $0.39 \pm 0.02$ & $2.4 \pm 0.2$ & 4.433 \\
\hline PEKI27 & $133.9 \pm 2.8$ & $68.70 \pm 1.02$ & $2.5 \pm 0.7$ & $0.6 \pm 0.1$ & $94.8 \pm 1.7$ & $174.0 \pm 3.6$ & $199.02 \pm 0.01$ & $0.9 \pm 0.3$ & $4.1 \pm 1.4$ & 1.987 \\
\hline PEKI28 & $71.9 \pm 1.5$ & $48.38 \pm 1.01$ & $-3.1 \pm 1.2$ & $1.2 \pm 0.1$ & $123.7 \pm 1.9$ & $258.4 \pm 3.9$ & $199.2 \pm 0.1$ & $0.6 \pm 0.3$ & - & -2.245 \\
\hline PEKI29 & $35.09 \pm 1.03$ & $6.9 \pm 1.05$ & $1.8 \pm 0.2$ & $0.8 \pm 0.2$ & $8.9 \pm 1.4$ & $122.3 \pm 2.2$ & $19.2 \pm 0.1$ & $0.3 \pm 0.2$ & $3.4 \pm 0.4$ & 3.586 \\
\hline
\end{tabular}

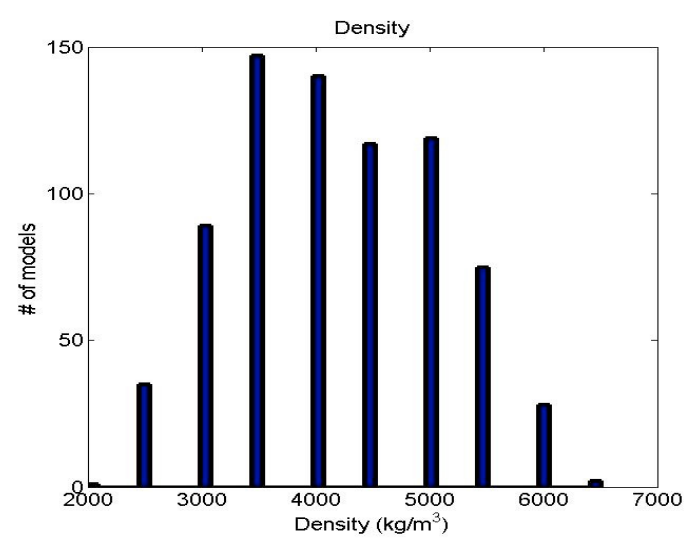

Fig. 21. Plot of good solutions for ELSL12. The best solution falls at $4500 \mathrm{~kg} \mathrm{~m}^{-3}$. The left bound is $2000 \mathrm{~kg} \mathrm{~m}^{-3}$ and the right bound is $6500 \mathrm{~kg} \mathrm{~m}^{-3}$.

density have relied on finding a single model which matches the observations, without searching for other combinations of the free parameters which might yield equally good fits. The number of meteors for which we have applied this modelling technique has been limited and we have analysed these in detail mainly to demonstrate the method at this stage. We note that our findings in terms of meteoroid physical properties should not be taken to represent the meteoroid population as a whole as our sampling is very biased by the requirements of complete trails.

Among 13 meteors in the first observing run and 29 meteors in the second run, only six satisfied the criteria of both starting and ending in the field of view of at least at one of the two stations (the necessary criteria to guarantee a complete lightcurve for an accurate photometric mass of the meteoroid). Among the six meteors, three with relatively low velocity were found to have very high densities. Taking into account fragmentation in determining the density of meteoroid does not, however, necessarily lead to higher values of meteoroid density, particularly when the heat of ablation of the meteoroid material is kept as a free parameter. The proportion of small meteoroids with high densities may be underestimated. It is possible these nearly pure iron meteoroids represent the impact pulverized remains from asteroids with ordinary chondrite compositions, a process which has been demonstrated in the lab to produce small, nearly pure iron particulates (Horz et al. 2005). Instruments with a narrow 
Table 13. Table showing where the best model fits occur among 151200 computed. Each model number has a modeled lightcurve and a modeled deceleration computed with values of the free parameters as shown. The comparison of the the modeled lightcurve with the observed one is represented by the value of the standard $\chi^{2}$ in the last column. We show here only the value of $\chi^{2}$ of lightcurve. (Meteor ELSL11).

\begin{tabular}{|c|c|c|c|c|c|c|c|c|c|}
\hline Model Num. & $\begin{array}{l}\text { Grain } \\
(\mathrm{kg})\end{array}$ & $\begin{array}{l}\text { Dens } \\
\left(\mathrm{kg} \mathrm{m}^{-3}\right)\end{array}$ & $\begin{array}{l}\text { Qf } \\
\left(\mathrm{J} \mathrm{kg}^{-1}\right)\end{array}$ & $\begin{array}{l}T_{\lim } \\
(\mathrm{K})\end{array}$ & $\begin{array}{l}T_{\text {boil }} \\
(\mathrm{K})\end{array}$ & $\begin{array}{l}\mathrm{Cps} \\
(\mathrm{J} / \mathrm{kg} \mathrm{K})\end{array}$ & $\begin{array}{l}\text { Molar m } \\
\text { au }\end{array}$ & $\begin{array}{l}\text { Therm } \\
(\mathrm{W} / \mathrm{m} \mathrm{K})\end{array}$ & $\begin{array}{l}\text { Chi square } \\
-\end{array}$ \\
\hline 9648 & $1.02 \mathrm{E}-12$ & 2000 & 5000000 & 1600 & 2000 & 800 & 20 & 0.2 & 0.0159509 \\
\hline 57335 & $1.34 \mathrm{E}-11$ & 1000 & 7000000 & 1600 & 1800 & 1000 & 36 & 1 & 0.0155439 \\
\hline 107489 & $1.78 \mathrm{E}-10$ & 1000 & 7000000 & 1350 & 1500 & 1200 & 30 & 0.5 & 0.0150817 \\
\hline 107719 & $1.78 \mathrm{E}-10$ & 1000 & 7000000 & 1600 & 1800 & 800 & 30 & 1 & 0.0155861 \\
\hline 107720 & $1.78 \mathrm{E}-10$ & 1000 & 7000000 & 1600 & 1800 & 800 & 36 & 0.2 & 0.0153506 \\
\hline 107721 & $1.78 \mathrm{E}-10$ & 1000 & 7000000 & 1600 & 1800 & 800 & 36 & 0.5 & 0.0133413 \\
\hline 107722 & $1.78 \mathrm{E}-10$ & 1000 & 7000000 & 1600 & 1800 & 800 & 36 & 0.7 & 0.0133309 \\
\hline 107723 & $1.78 \mathrm{E}-10$ & 1000 & 7000000 & 1600 & 1800 & 800 & 36 & 1 & 0.0135701 \\
\hline 107733 & $1.78 \mathrm{E}-10$ & 1000 & 7000000 & 1600 & 1800 & 1000 & 36 & 0.5 & 0.0134306 \\
\hline 107734 & $1.78 \mathrm{E}-10$ & 1000 & 7000000 & 1600 & 1800 & 1000 & 36 & 0.7 & 0.0138667 \\
\hline 107735 & $1.78 \mathrm{E}-10$ & 1000 & 7000000 & 1600 & 1800 & 1000 & 36 & 1 & 0.0145663 \\
\hline 107749 & $1.78 \mathrm{E}-10$ & 1000 & 7000000 & 1600 & 2000 & 800 & 20 & 0.5 & 0.0149821 \\
\hline 107750 & $1.78 \mathrm{E}-10$ & 1000 & 7000000 & 1600 & 2000 & 800 & 20 & 0.7 & 0.0148833 \\
\hline 107751 & $1.78 \mathrm{E}-10$ & 1000 & 7000000 & 1600 & 2000 & 800 & 20 & 1 & 0.0146845 \\
\hline 107902 & $1.78 \mathrm{E}-10$ & 1000 & 7000000 & 1700 & 1800 & 800 & 36 & 0.7 & 0.0146738 \\
\hline 107935 & $1.78 \mathrm{E}-10$ & 1000 & 7000000 & 1700 & 2000 & 800 & 30 & 1 & 0.0127871 \\
\hline 107947 & $1.78 \mathrm{E}-10$ & 1000 & 7000000 & 1700 & 2000 & 1000 & 30 & 1 & 0.0157451 \\
\hline 110169 & $1.78 \mathrm{E}-10$ & 2000 & 5000000 & 1350 & 1500 & 800 & 36 & 0.5 & 0.0157533 \\
\hline 110170 & $1.78 \mathrm{E}-10$ & 2000 & 5000000 & 1350 & 1500 & 800 & 36 & 0.7 & 0.015838 \\
\hline 150479 & $1.32 \mathrm{E}-09$ & 8000 & 7000000 & 900 & 2100 & 1200 & 36 & 1 & 0.0148818 \\
\hline 150497 & 1.32E-09 & 8000 & 7000000 & 1200 & 1500 & 1000 & 30 & 0.5 & 0.0137643 \\
\hline 150647 & $1.32 \mathrm{E}-09$ & 8000 & 7000000 & 1200 & 2100 & 1000 & 36 & 1 & 0.0143968 \\
\hline 150654 & 1.32E-09 & 8000 & 7000000 & 1200 & 2100 & 1200 & 30 & 0.7 & 0.0150633 \\
\hline 150655 & $1.32 \mathrm{E}-09$ & 8000 & 7000000 & 1200 & 2100 & 1200 & 30 & 1 & 0.0157368 \\
\hline 150657 & 1.32E-09 & 8000 & 7000000 & 1200 & 2100 & 1200 & 36 & 0.5 & 0.0145784 \\
\hline 150658 & $1.32 \mathrm{E}-09$ & 8000 & 7000000 & 1200 & 2100 & 1200 & 36 & 0.7 & 0.0136402 \\
\hline 150791 & 1.32E-09 & 8000 & 7000000 & 1350 & 2000 & 1000 & 36 & 1 & 0.0157127 \\
\hline 150802 & 1.32E-09 & 8000 & 7000000 & 1350 & 2000 & 1200 & 36 & 0.7 & 0.015931 \\
\hline 150815 & $1.32 \mathrm{E}-09$ & 8000 & 7000000 & 1350 & 2100 & 800 & 36 & 1 & 0.0154001 \\
\hline 150823 & 1.32E-09 & 8000 & 7000000 & 1350 & 2100 & 1000 & 30 & 1 & 0.0147547 \\
\hline 150826 & $1.32 \mathrm{E}-09$ & 8000 & 7000000 & 1350 & 2100 & 1000 & 36 & 0.7 & 0.0141959 \\
\hline 150827 & 1.32E-09 & 8000 & 7000000 & 1350 & 2100 & 1000 & 36 & 1 & 0.014417 \\
\hline 150833 & $1.32 \mathrm{E}-09$ & 8000 & 7000000 & 1350 & 2100 & 1200 & 30 & 0.5 & 0.0150649 \\
\hline 150834 & 1.32E-09 & 8000 & 7000000 & 1350 & 2100 & 1200 & 30 & 0.7 & 0.0149307 \\
\hline 150837 & $1.32 \mathrm{E}-09$ & 8000 & 7000000 & 1350 & 2100 & 1200 & 36 & 0.5 & 0.0135317 \\
\hline 150992 & 1.32E-09 & 8000 & 7000000 & 1600 & 2100 & 800 & 36 & 0.2 & 0.0141078 \\
\hline 150993 & $1.32 \mathrm{E}-09$ & 8000 & 7000000 & 1600 & 2100 & 800 & 36 & 0.5 & 0.013374 \\
\hline 150994 & 1.32E-09 & 8000 & 7000000 & 1600 & 2100 & 800 & 36 & 0.7 & 0.0154664 \\
\hline 151004 & $1.32 \mathrm{E}-09$ & 8000 & 7000000 & 1600 & 2100 & 1000 & 36 & 0.2 & 0.0133828 \\
\hline 151005 & 1.32E-09 & 8000 & 7000000 & 1600 & 2100 & 1000 & 36 & 0.5 & 0.0158163 \\
\hline 151016 & $1.32 \mathrm{E}-09$ & 8000 & 7000000 & 1600 & 2100 & 1200 & 36 & 0.2 & 0.0135423 \\
\hline
\end{tabular}
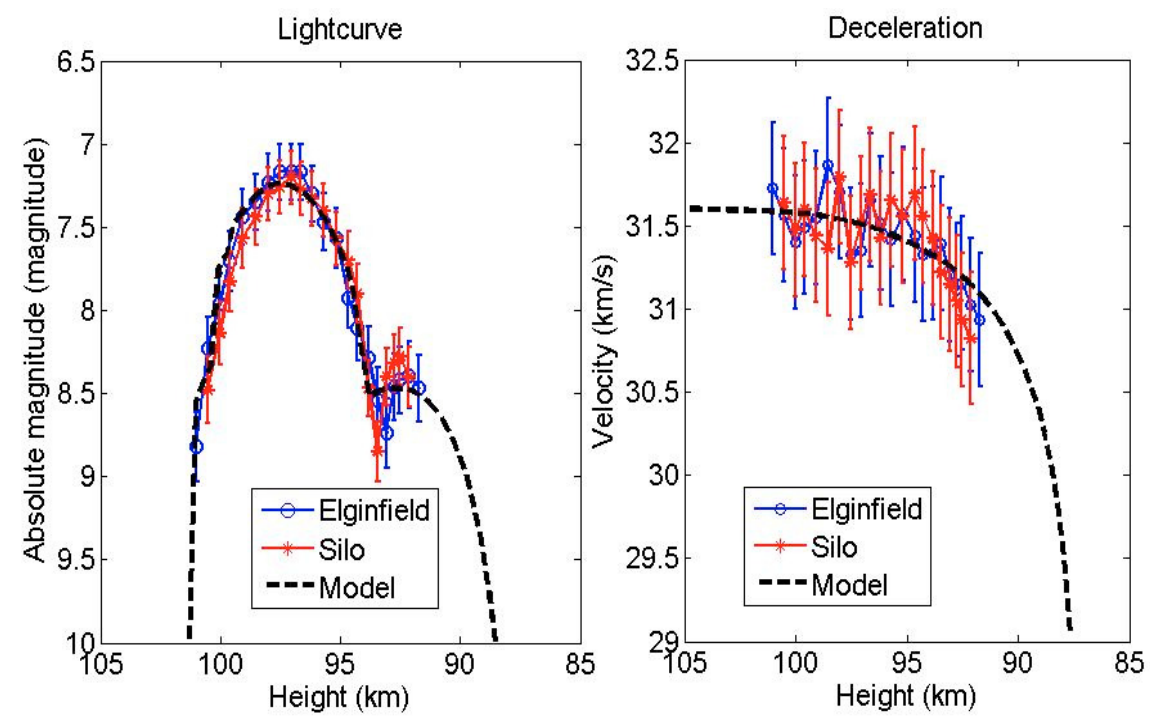

Fig. 22. Lightcurve and deceleration of ELSL12, shown together with the best fitting model. 


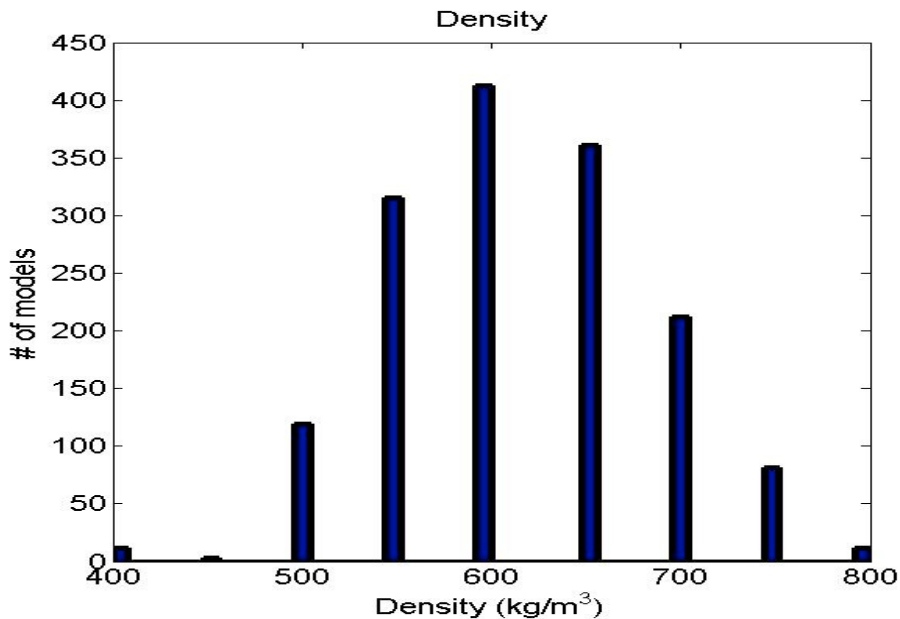

Fig. 23. Plot of good solutions for PEKI08. The best solution falls at $600 \mathrm{~kg} \mathrm{~m}^{-3}$. The left bound is $400 \mathrm{~kg} \mathrm{~m}^{-3}$ and the right bound is $800 \mathrm{~kg} \mathrm{~m}^{-3}$.
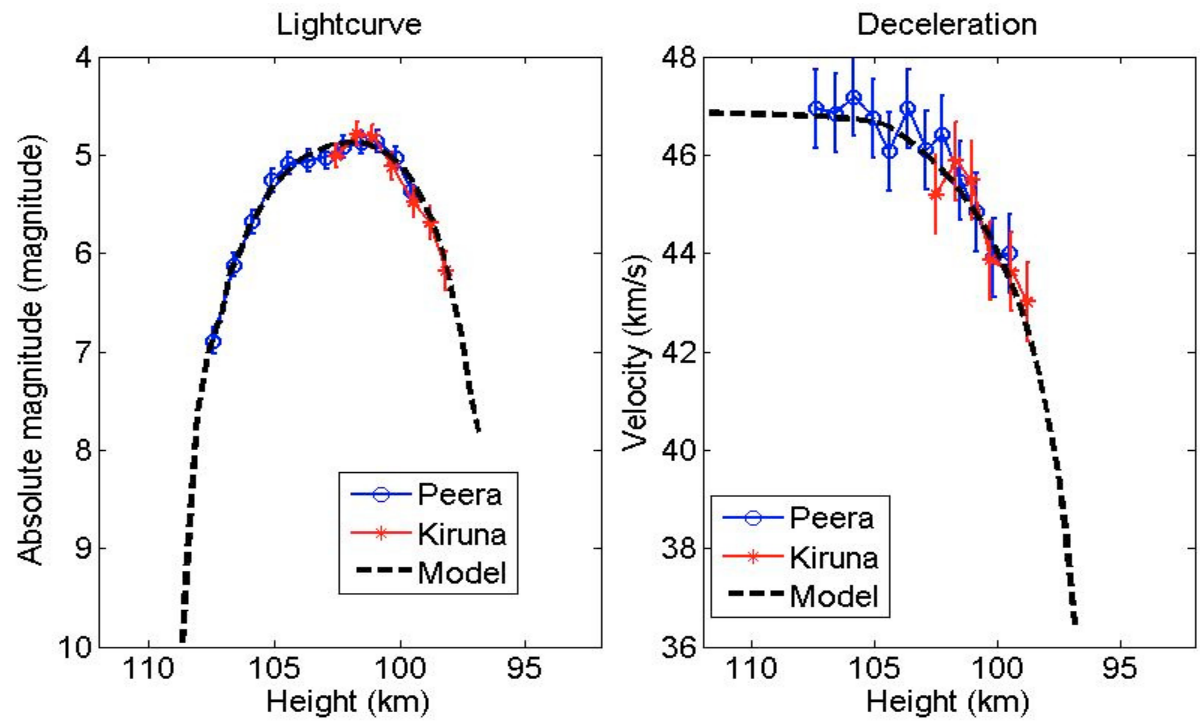

Fig. 24. Lightcurve and deceleration of PEKI08, with the best fitting model.

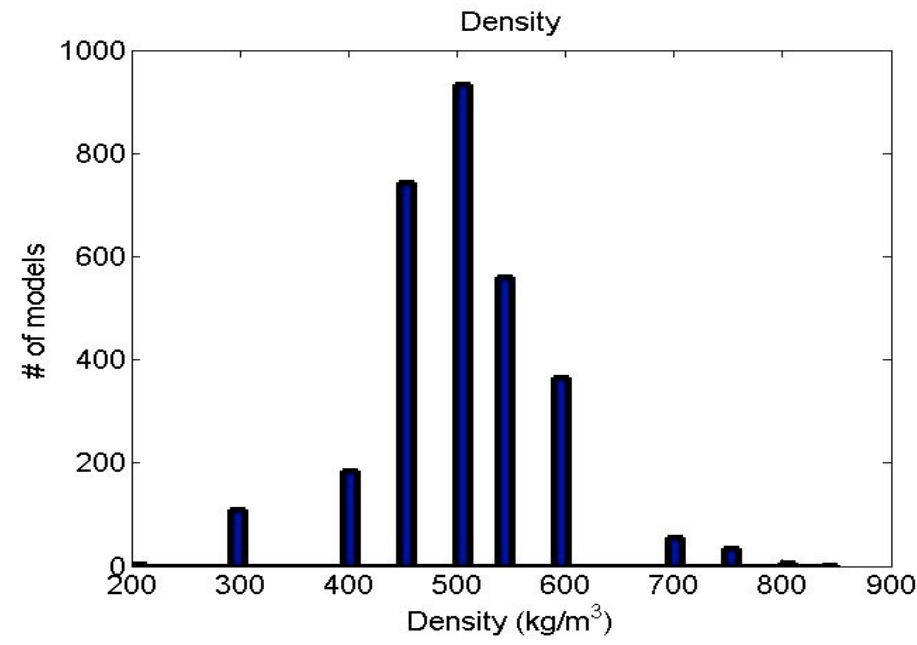

Fig. 25. Plot of good solutions for PEKI09. The best solution falls at $500 \mathrm{~kg} \mathrm{~m}^{-3}$. The left bound is $200 \mathrm{~kg} \mathrm{~m}^{-3}$ and the right bound is $800 \mathrm{~kg} \mathrm{~m}^{-3}$.

field of view and very high sensitivity are able to record these very faint meteoroids. Apart from the small number statistics in this study, our observations were biased toward slow, dense meteoroids which ablate low in the atmosphere and therefore have shorter trails, more likely to begin and end in the field of view.
Precise measurements of deceleration provide a very important constraint in determining meteoroid density. For small meteoroids, both the photometric and dynamic data are needed to adequately constrain ablation models. High velocity meteoroids typically only show deceleration at the very end of their 

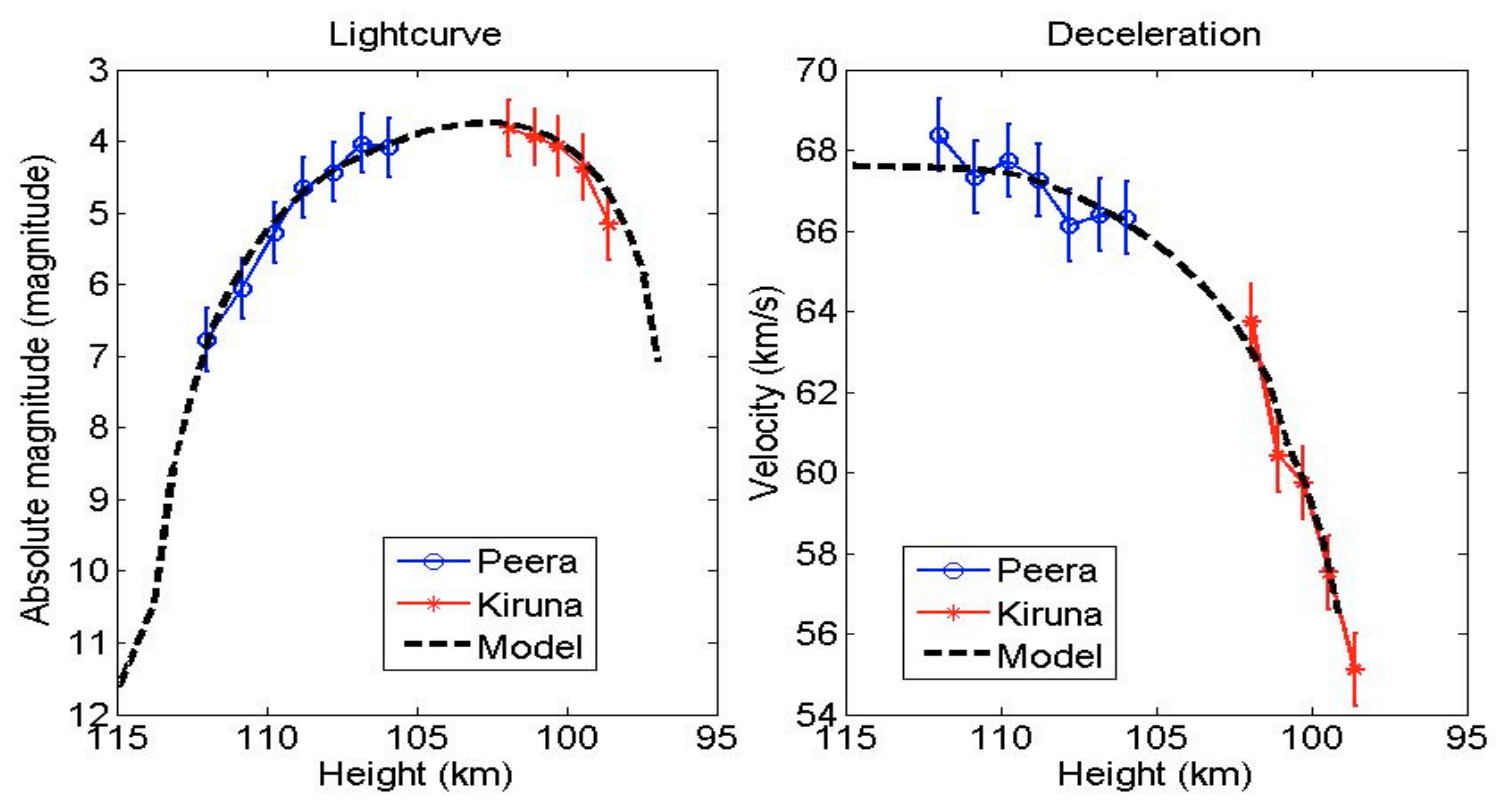

Fig. 26. Lightcurve and deceleration of PEKI09, with the best fitting model.

trajectory, with most of the energy transfer being used for ablation and very little going in to changing the velocity, making deceleration difficult to measure. The equipment used in this investigation is capable of detecting very small decelerations, but the number of usable meteors is small because of the very small fields of view. The next step will be to see if standard meteor video cameras, with fields of view in the 15 to 30 degree range, can measure the deceleration with enough accuracy to constrain the model parameters, particularly density. If so, many more meteor densities will be determined, giving the statistics needed for an analysis of the average composition of meteoroids.

Acknowledgements. J.B.K. thanks the Vatican Observatory for funding support and Guy Consolmagno for help in manuscript preparation. The authors also thank Kyle Hill, Ashley Faloon, Leslie Rogers and Nicole Kaiser for their help in collection of data as well as Jiri Borovicka and Zdenek Ceplecha for use of their software. P.G.B., MDC and R.L.H. thank the Natural Sciences and Engineering Research Council for funding support for this work.

\section{References}

Babadzhanov, P. B. 2002, A\&A, 384, 317

Beech, M. 1986, AJ, 91, 159

Beech, M., \& Murray, I. S. 2003, MNRAS, 345, 696

Beech, M., Illingworth, A., \& Murray, I. S. 2003, M\&PS, 38, 1045

Bellot Rubio, L. R., Martinez Gonzalez, M. J., Ruiz Herrera, L., et al. 2002, A\&A, 389, 680
Bevington, P. R., \& Robinson, D. K. 2003, Data Reduction and Error Analysis for the Physical Science (New York: McGraw-Hill), 313

Borovicka, J. 1990, Bull. Astr. Inst. Czechosl., 41, 391

Borovicka, J. P., Koten, P., Spurny, P., Bocek, J., \& Stork, R. 2005, Icarus, 174, 15

Borovicka, J. 2005, Proceedings of the International Astronomy Union (Cambridge University Press), 1, 249

Borovicka, J., Spurny, P., \& Koten, P. 2007, A\&A, 473, 661

Campbell, M. P., Brown, A., Leblanc, R., et al. 2000, M\&PS, 35, 1259

Campbell-Brown, M. D., \& Koschny, D. 2004, A\&A, 418, 751

Ceplecha, Z. 1968, SAO Special Rep., 279, 1

Ceplecha, Z. 1987, Bull. Astron. Inst. Czech., 38, 4, 222

Ceplecha, Z. 1988, Bull. Astron. Inst. Czech., 39, 4, 221

Ceplecha, Z. J., Borovicka, W. G., Elford, D. O., et al. 1998, Space Sci. Rev., 84, 327

Fisher, A. A., Hawkes, R. L., Murray, I. S., Campbell, M. D., \& LeBlanc, A. G. 2000, Planetary and Space Sci., 48, 911

Hapgood, M., Rothwell, P., \& Royrvik, O. 1982, MNRAS, 201, 569

Hawkes, R. L. 2002, Meteors in the Earth's atmosphere, ed. E. Murad, \& I. P. Williams, 97

Hawkes, R. L., \& Jones, J. 1975, MNRAS, 173, 339

Hedin, A. 1991, J. Geophys. Res. 96, 1154

Hörz, F., Cintala, M. J., See, T. H., \& Le, L. 2005, M\&PS, 40, 1329

Koten, P., Borovička, J., Spurny, P., Betlem, H., \& Evans, S. 2004, A\&A, 428, 683

Lebedinets, V. N., \& Portnyagin, Yu. I. 1968, SvA AJ, 11, 700

Hill, K. A., Rogers, L. A., \& Hawkes, R. L. 2005, A\&A, 444, 615

Myers, J. R., Sande, C. B., Miller, A. C., Warren, W. H., Jr, \& Tracewell, D. A. 2001, yCat, 5109

Popova, O. P. 2004, Earth, Moon, and Planets 95, 303

Revelle, D. O. 2001, in Proc. Meteoroids 2001 Conf., ed. B. Warmbein, Kiruna, Sweden, ESA-SP, 495, 513

Whipple, F. L., \& Jacchia, L. G. 1957, Smithsonian Contr. Astrophysics, 1, 183 